\title{
Three Common Symbiotic ABC Subfamily B Transporters in Medicago truncatula Are Regulated by a NIN-Independent Branch of the Symbiosis Signaling Pathway
}

\author{
Sonali Roy, ${ }^{1}$ Andrew Breakspear, ${ }^{1}$ Donna Cousins, ${ }^{1}$ Ivone Torres-Jerez, ${ }^{2}$ Kirsty Jackson, ${ }^{1}$ Anil Kumar, ${ }^{3}$ \\ Yangyang Su, ${ }^{4}$ Cheng-Wu Liu, ${ }^{1}$ Nick Krom, ${ }^{2}$ Michael Udvardi, ${ }^{2}$ Ping Xu, ${ }^{4, \dagger}$ and Jeremy D. Murray ${ }^{1,3, \dagger}$ \\ 1 John Innes Centre, Norwich, NR4 7UH, U.K. \\ ${ }^{2}$ Noble Research Institute, Ardmore, OK 73401, U.S.A. \\ ${ }^{3}$ CAS-JIC Centre of Excellence for Plant and Microbial Science (CEPAMS), Centre for Excellence in Molecular Plant Sciences \\ (CEMPS), Chinese Academy of Sciences, 300 Feng Lin Road, Shanghai 200032, China \\ ${ }^{4}$ Shanghai Engineering Research Center of Plant Germplasm Resource, College of Life Sciences, Shanghai Normal University, \\ Shanghai 200234, China
}

Accepted 28 March 2021.

Several ATP-binding cassette (ABC) transporters involved in the arbuscular mycorrhizal symbiosis and nodulation have been identified. We describe three previously unreported ABC subfamily B transporters, named AMN1, AMN2, and AMN3 (ABCB for mycorrhization and nodulation), that are expressed early during infection by rhizobia and arbuscular mycorrhizal fungi. These ABCB transporters are strongly expressed in symbiotically infected tissues, including in root-hair cells with rhizobial infection threads and arbusculated cells. During nodulation, the expression of these genes is highly induced by rhizobia and purified Nod factors and is dependent on DMI3 but is not dependent on other known major regulators of infection, such as NIN, NSP1, or NSP2. During mycorrhization their expression is dependent on DMI3 and RAM1 but not on NSP1 and NSP2. Therefore, they

${ }^{\dagger}$ Corresponding authors: P. Xu; pingxu_ardnor@shnu.edu.cn and J. D. Murray: jeremy.murray@jic.ac.uk

Funding: This work was funded by grants from the Shanghai Engineering Research Center of Plant Germplasm Resources (grant number 17DZ2252700) to P. Xu, and grants from the Ministry of Science and Technology (2019FA0904703), Strategic Priority Research Program of the Chinese Academy of Sciences (XDB27040209), and National Key R\&D Program of China (2016YFA0500500), the Chinese Academy of Science (153D31KYSB20160074), and BBSRC (David Philips Fellowship BB/L010305/1) to J. D. Murray. S. Roy was supported by a grant from the John Innes Foundation.

Current address for S. Roy: College of Agriculture, Tennessee State University, TN 37209, U.S.A.

Current address for C.-W. Liu: Hefei National Laboratory for Physical Sciences at the Microscale, School of Life Sciences, Division of Life Sciences and Medicine, University of Science and Technology of China, 443 Huangshan Road, Hefei 230027, China

*The $\boldsymbol{e}$-Xtra logo stands for "electronic extra" and indicates there are supplementary materials published online.

The author(s) declare no conflict of interest. distributed under the CC BY-NC-ND 4.0 International license. may be commonly regulated through a distinct branch of the common symbiotic pathway. Mutants with exonic Tnt1-transposon insertions were isolated for all three genes. None of the single or double mutants showed any differences in colonization by either rhizobia or mycorrhizal fungi, but the triple amn1 amn2 amn3 mutant showed an increase in nodule number. Further studies are needed to identify potential substrates of these transporters and understand their roles in these beneficial symbioses.

Keywords: ABCB type transporter, arbuscular mycorrhizal symbiosis, auxin, legumes, Medicago, root nodule symbiosis

Legumes can associate with beneficial microbes, including rhizobia and arbuscular mycorrhizae (AM), to acquire nutrients from their environment. Under nitrogen-limiting conditions, legumes, such as the model plant Medicago truncatula, cooperate with rhizobia to convert atmospheric $\mathrm{N}_{2}$ into plant-usable ammonia in exchange for carbon (Roy et al. 2020). Similarly, if phosphate availability is low, almost $70 \%$ of all land plants, including legumes, form associations with soil fungi belonging to the phylum Glomeromycota that provide them with inorganic phosphate (Gutjahr and Parniske 2013; van der Heijden et al. 2015). Understanding how these associations are formed can allow fine-tuning of these symbioses in an agricultural context to reduce fertilizer inputs and thereby reduce the unsustainable use of fossil fuels. Although the two symbioses differ in many aspects, in both cases, the symbionts colonize host roots through intracellular infection using many of the same host factors.

During root nodule (RN) symbiosis, host secretion of flavonoids into the rhizosphere induces rhizobia to produce lipochitooligosaccharide (LCO) molecules called Nod factors (NFs). The combination of host flavonoid signatures and symbiont-specific NFs mediate highly specific legume-rhizobia interactions, with compatible rhizobia and hosts responding only to specific flavonoids and NFs, respectively (Liu and Murray 2016). Upon perception of NFs, two simultaneous but genetically separable processes occur-intracellular infection and nodule organogenesis. The rhizobia attach to root hairs and produce NFs that trigger calcium oscillations in the host cell and leads to root-hair curling and entrapment of the bacteria in microcolonies in a so-called 
'infection pocket' (Fournier et al. 2015). In Medicago, two lysin motif (LysM) domain-containing receptor kinase genes, NOD FACTOR PERCEPTION (NFP) and LySM RECEPTOR KINASE3 ( $L Y K 3)$, are required for $\mathrm{RN}$ symbiosis to commence; mutations in these genes abolish nodulation at the early stages (Madsen et al. 2003; Radutoiu et al. 2003; Smit et al. 2007). Rhizobial infection involves the hormones auxin and cytokinin, which play positive and negative roles, respectively (Breakspear et al. 2014; Buhian and Bensmihen 2018; Held et al. 2014; Jardinaud et al. 2016; Murray et al. 2007; Tirichine et al. 2007). Auxin markers suggest that an auxin maximum is formed in root hairs during rhizobial infection, and genetic and pharmacological evidence suggests that auxin biosynthesis and signaling are required for infection (Breakspear et al. 2014; Nadzieja et al. 2019). Along with their roles in infection, these hormones also activate mitosis in cortical cells to form a nodule primordium (Guan et al. 2013; Liu et al. 2015; Murray et al. 2007; Ng et al. 2015; Roy et al. 2017; Schiessl et al. 2019; Suzaki et al. 2012). The infection threads grow toward the developing primordia and rhizobia are released into the inner cells of the nodule via an endocytotic-type mechanism that encapsulates the bacteria within host membrane, in which they differentiate and begin to fix atmospheric $\mathrm{N}_{2}$.

Interaction of plants with arbuscular mycorrhizal fungi is contingent on low phosphate conditions, and, like nodulation, it begins with an exchange of signals between the plant host and the fungal symbiont (MacLeanet al. 2017; Müller and Harrison 2019). When phosphate availability is low, plants secrete strigolactones, which stimulate fungal spore germination and hyphal elongation (Akiyama and Hayashi 2006; Genre et al. 2013; Kretzschmar et al. 2012). Like the bacterial symbionts, AM fungi then produce LCOs that trigger perinuclear calcium oscillations in the host and initiate downstream developmental pathways (Feng et al. 2019; Hürter et al. 2018). Once the AM fungal hypha reaches the root surface, it penetrates through a non-root hair cell and then colonizes the root apoplast. Once it reaches the inner cell layers, the hyphae form a branched intracellular structure called an arbuscule, which is the primary site for nutrient exchange between the host and symbiont (Luginbuehl and Oldroyd 2017; Wang et al. 2017). As the arbuscule develops, the plasma membrane of the host cell invaginates to surround it, forming what is called the peri-arbuscular membrane (PAM), across which phosphorus and other nutrients are exchanged (Pumplin and Harrison 2009). The characteristics of the PAM are unique, as illustrated by the observation that the symbiotic phosphate transporter MtPT4 localizes specifically to the PAM and is absent from the surrounding cell membrane (Pumplin et al. 2012).

Despite the greatly contrasting developmental outcomes, both nodulation and mycorrhization employ a common core set of genes (Parniske 2008). The molecular machinery downstream of NF and Myc factor recognition involves at least 12 'common symbiotic' genes. The kinase MtDMI2/LjSYMRK (DOES NOT MAKE INFECTION 2/SYMBIOSIS RECEPTOR KINASE) putatively acts as a coreceptor for LysM domain-containing receptors and is required for both rhizobial and mycorrhizal signaling (Gherbi et al. 2008). Downstream of these recognition events, the cation channels CASTOR and POLLUX in Lotus japonicus and the POLLUX ortholog DMI1 (DOES NOT MAKE INFECTION 1) in M. truncatula are required for nuclear calcium oscillations that serve as signatures that help distinguish the incoming microbe (Charpentier et al. 2008; Riely et al. 2007). Mutations in these genes affect both rhizobial and mycorrhizal colonization of the plant (Chen et al. 2007). Calcium spiking requires the activity of three cyclic nucleotide gated channels, mutations in which both forms of symbioses are strongly impaired (Charpentier et al. 2016). Calcium signatures are interpreted by the central regulator of symbiosis signaling calcium calmodulin kinase (CCaMK) in L. japonicus or its ortholog DMI3 in M. truncatula. Activation of this regulatory kinase is sufficient to initiate nodule organogenesis and initiate formation of the prepenetration apparatus that develops during mycorrhizal colonization (Gleason et al. 2006; Takeda et al. 2012). CCaMK interacts with LjCYCLOPS or MtIPD3 and MtIPD3-like that are essential for infection thread formation, nodule organogenesis, and arbuscular mycorrhizal associations (Horváth et al. 2011; Jin et al. 2018; Yano et al. 2008). A suite of GRAS domain-containing transcription factors act downstream of $\mathrm{CCaMK}$ to control both nodule formation and arbuscular mycorrhizal associations (Hartmann et al. 2019; Hirsch and Oldroyd 2009), including NSP1 and NSP2, which play essential roles in both nodulation and mycorrhization (Delaux et al. 2013; Hirsch et al. 2009; Kalo et al. 2005; Liu et al. 2011; Smit et al. 2005). Another GRAS protein, RAM1 (REQUIRED FOR ARBUSCULAR MYCORRHIZATION 1), is involved solely in mycorrhization (Gobbato et al. 2012). In nodulation, the founding member of the NIN-like protein transcription factor family NODULE INCEPTION (NIN) is specifically required for nodulation (Gobbato et al. 2012; Schauser et al. 1999). The only other common symbiotic genes known encode the major sperm domain-containing protein VAPYRIN and the protein with which it interacts, LUMPY INFECTIONS (LIN)/CERBERUS, which are involved in infection thread progression and arbuscule formation (Murray et al. 2011; Pumplin et al. 2010). In addition to LIN, VAPYRIN interacts with a component of the EXOCYST, suggesting the involvement of exocytotic processes during symbiotic infection (Liu et al. 2019b).

Several studies over the past decade have reported ATP-binding cassette $(\mathrm{ABC})$ transporters to be important players in the beneficial symbioses. In particular, members of subfamily $\mathrm{G}$ have been found to have diverse roles in arbuscular mycorrhizal symbiosis at different stages of the association. One example is the Petunia $\times$ hybrida strigolactone transporter PhPDR1 that was shown to be required for initial establishment of symbiosis with mycorrhizal fungi (Kretzschmar et al. 2012). Its closest homolog in Medicago, MtABCG59, is not essential for nodulation but is required for arbuscular mycorrhization (Banasiak et al. 2020). Two periarbuscular membrane-localized half-ABCG transporters, STR1 and STR2, were shown to be essential for arbuscule development in $M$. truncatula, mutations in which lead to prematurely degenerating arbuscules (Käll et al. 2004; Zhang et al. 2010). Mutants of the orthologous transporters in rice phenocopied the stunted arbuscule morphology observed in the strl mutants (Gutjahr et al. 2012), indicating an evolutionarily conserved function across angiosperms. Knockdown of the M. truncatula ABC transporter MtABCG10, using RNA interference, reduced the amount of isoflavonoids released into the root exudate (Banasiak et al. 2013). During nodule development, $L j A B C B 1$ was shown to be expressed in uninfected cells of the nodule. Yeast cells expressing $L j A B C B 1$ accumulated less auxin, suggesting it may encode an auxin efflux transporter (Takanashi et al. 2012). The recently identified MtABCG56 is a plasma membrane-localized cytokinin exporter expressed in Medicago roots and nodules required for optimal nodulation (Jarzyniak et al. 2021).

To date, no ABC transporters have been reported having a role in both symbioses (Roy et al. 2020). In this study, we characterized the larger full-size $\mathrm{ABC}$ family, and, using available transcriptomic data, we identified three symbiosis-responsive ABCB transporters expressed during both nodulation and mycorrhization. We investigated these candidates by analyzing their temporal and spatial expression patterns, gene regulation, and by investigating their role in symbiosis using Tnt1 insertion mutants.

\section{RESULTS}

Three ABCB members are induced during symbiosis.

To identify the members of the ABC transporter family, we mined the latest $M$. truncatula genome version v4.0_reanno and 
genome V5 (de Bang et al. 2017; Pecrix et al. 2018). From this search, we identified 110 full-size $\mathrm{ABC}$ transporters containing two transmembrane domains and two nucleotide-binding cytosolic domains, which is almost double that of Arabidopsis, which has 54 (Supplementary Table S1; Supplementary Fig. S1). Given the inability of Arabidopsis to interact with rhizobia and arbuscular mycorrhizal fungi, we hypothesized that either expansion of this group of transporters, the retention of these genes in Medicago, or both might reflect specialized roles for some members of this family in these symbioses. Using published RNAseq and microarray data on the Medicago truncatula small secreted proteins database and the Medicago Gene Expression Atlas as our guide, we identified a total of $53 \mathrm{ABC}$ transporters (full and half size) that were significantly up- or downregulated during both rhizobial and mycorrhizal infection (Fig. 1). Three ABC transporters belonging to subfamily $\mathrm{B}$, which we designated as $\mathrm{ABCB}$ transporters in mycorrhization and nodulation $(A M N)$ genes AMN1 (Medtr3g086430, MtrunA17_Chr3g0123411, Affymetrix probeset Mtr.1103.1.S1_at), AMN2 (Medtr4g081190, MtrunA17_Chr4g0041871, probeset Mtr.44070.1.S1_at), and

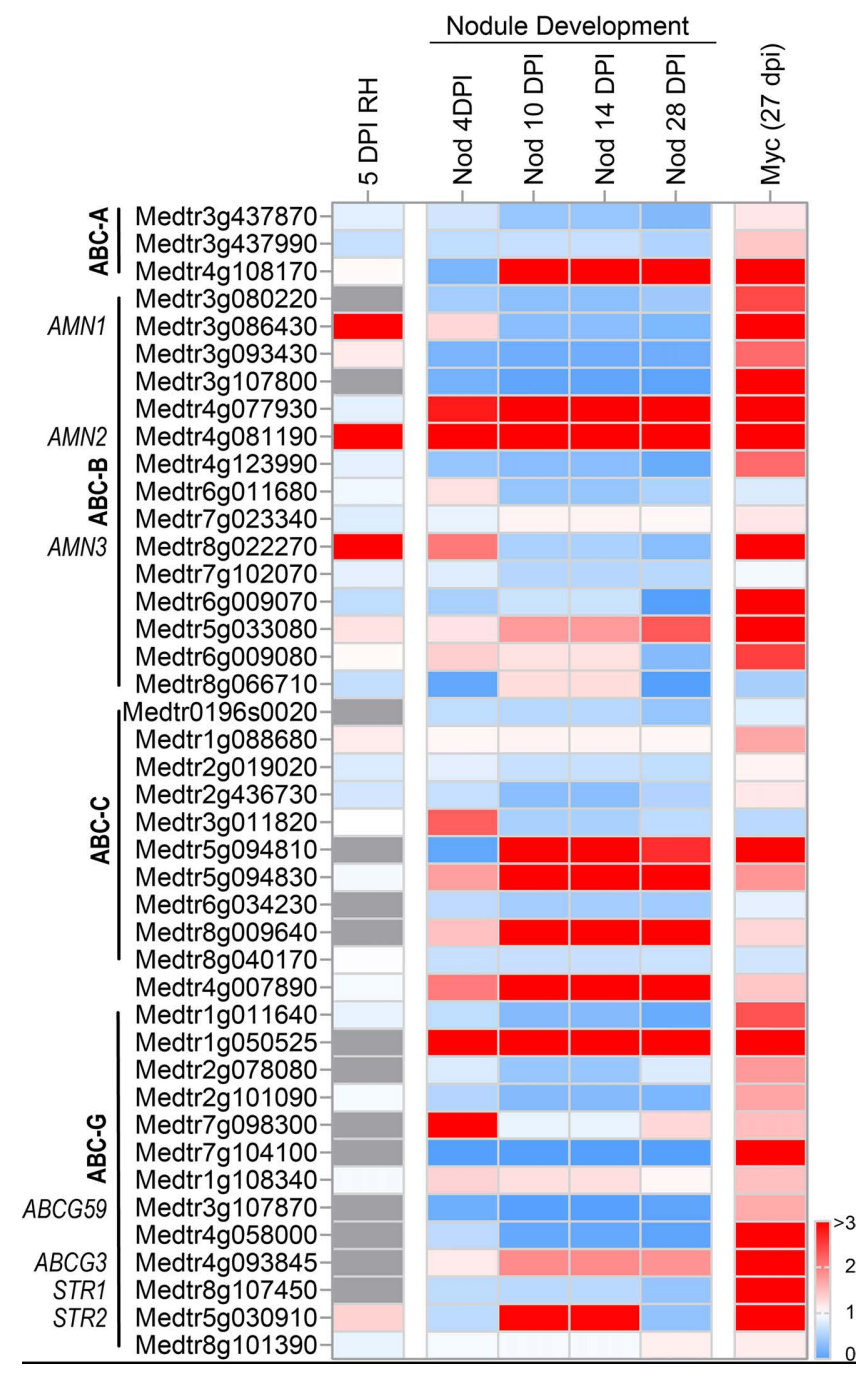

Fig. 1. Heatmap showing expression values of all $\mathrm{ABC}$ transporters that are differentially regulated during mycorrhizal or rhizobial symbiosis or both. Raw values were taken from published datasets for Rm1021 infected root hairs, nodule development, and Rhizophagus irregularis infected roots (Breakspear et al. 2014; de Bang et al. 2017). Myc = Medicago truncatula roots infected with $R$. irregularis at 27 days postinoculation (Luginbuehl et al. 2017). Fold change values are displayed, $P$ value $<0.05$. ABC transporters with known roles in arbuscular mycorrhizal symbiosis are indicated.
AMN3 (Medtr8g022270, MtrunA17_Chr8g0344651, probeset Mtr.46524.1.S1_at), showed enhanced expression during mycorrhizal infection in whole roots and in root hairs infected with rhizobia (Fig. 1). Importantly, these genes were not responsive to any known pathogens and were not induced during any stage of vegetative growth, suggesting a specialized role for these transporters in symbiotic infection (Supplementary Fig. S2). Two of the transporters, AMN1 and AMN2, are close homologs, while AMN3 grouped separately from all other Medicago subfamily B members (Supplementary Fig. S1). All three are predicted to have 12 integral membrane-spanning domains and are predicted to localize to the plasma membrane using pLOC V2 (Chou and Shen 2010).

We then determined the relative expression of these genes over a time course in roots inoculated with Rhizophagus irregularis. Arbuscules and vesicles were counted, using the gridintersection method to get an estimate of the percentage of colonization. The transcript levels were determined for eight timepoints (Fig. 2A), including one timepoint $(14+14$ dpi [days postinoculation]) in which the plants were grown for two weeks in lownutrient soil in the presence of mycorrhizal fungi and then were transferred to full nutrient-containing soil for two additional weeks. At 3 dpi, at which point the plants were just beginning to be colonized and showed less than $1 \%$ colonization, the $A M N$ genes were not induced. The expression of all three genes was strongly correlated with the estimated colonization levels (Fig. 2A). When infected plants were transferred to phosphatereplete soil from low-nutrient soil, the expression of the $A M N$ genes was dramatically reduced and was almost undetectable, despite the presence of arbuscules and vesicles in the roots (Fig. 2A). This suggests that the expression of $A M N$ genes may be associated with actively progressing infection or is negatively regulated by phosphate. We then isolated infected root hairs from M. truncatula wild-type (WT) Jemalong A17 seedlings inoculated with Sinorhizobium meliloti (Rm2011), as described by Breakspear et al. (2014) and estimated the transcript abundance of $A M N 1, A M N 2$, and $A M N 3$. Their expression was compared with that of root hairs infected with the non-NF-producing strain SL44 (Rm1021 $\triangle$ nodD1ABC). The $A M N$ transcripts were detected in control root hairs at very low abundance and were significantly increased upon infection (Fig. 2B). Finally, we quantified the transcript abundance of these genes in excised M. truncatula Jemalong A17 nodules over time compared with uninoculated root segments from the infection zone (Fig. 2C). All three $A M N$ genes were induced in 4-dpi nodule bumps, suggesting they were involved in early stages of RN symbiosis, i.e., the ramification of infection threads, nodule organ initiation, or expansion. Their transcript abundance subsequently decreased over time compared with uninoculated roots. This expression pattern, peaking at $4 \mathrm{dpi}$ and then lower in mature nodules, is typical for infection genes, such as ERNI and NF-YAl (Combier et al. 2006). This expression pattern is due to the fact that, as the nodule develops, the infection zone becomes limited to the nodule apex, and the interzone and $\mathrm{N}_{2}$-fixation zone comprise the bulk of the nodule tissue. Finally, addition of $6 \mathrm{mM}$ nitrogen had no measurable effect on the expression of the $A M N$ genes at $14 \mathrm{dpi}$ (Fig. 2D).

\section{Spatial expression of $A M N$ genes is associated with rhizobial and mycorrhizal infection structures.}

The AMN1 (-1,448 bps), AMN2 (-3,017 bps), and AMN3 $(-2,498$ bps $)$ promoters were assessed for their spatio-temporal expression patterns in $M$. truncatula transgenic roots using promoter- $\beta$-glucuronidase (GUS) fusions in Agrobacterium rhizogenes transformed hairy roots. In general, $A M N 1$ and $A M N 2$ promoters showed overlapping patterns of expression with variations in the spread and the strength of expression. Expression of $A M N 2$ and $A M N 3$ was detected within a few hours of staining 
(6 to $8 \mathrm{~h}$ ), whereas $A M N 1$ required longer staining procedures to detect lower levels of GUS activity (overnight staining). At 10 dpi with rhizobia, $A M N 1$ expression was associated with root hairs forming infection pockets or those containing an infection thread (Fig. 3). This included GUS activity in some root hairs adjacent to infected root hairs. AMN2 showed a similar pattern of expression and was also associated with root-hair cells containing infection structures. Expression of AMN2 was not detected in root hairs lacking infection structures. Similarly, $A M N 3$ expression was associated with infected root hairs containing microcolonies (Fig. 3). In uninfected plants, low-level expression of all three $A M N$ genes was detected in vascular tissue, lateral root primordia, and the root tip (Supplementary Fig. S3).

We also monitored the expression of the $A M N$ genes in mycorrhizal roots. No expression of the AMNs was observed upon hyphal penetration of the root surface (Fig. 3). After 4 weeks, we observed induction of $A M N 1$ in arbuscule-containing cells, but its expression was not associated with intercellular hyphae or vesicles. $A M N 2$ and $A M N 3$ were induced very strongly in arbuscule-containing cells but, as was the case with $A M N 1$, their expression was not associated with intercellular hyphae (Fig. 3).

\section{$A M N 1, A M N 2$, and $A M N 3$ are restricted} to mycorrhizal angiosperms.

To determine the phylogenetic distribution of the AMNs, we looked for orthologs in other plant species. We found that the AMNs did not cluster together with any previously characterized members of the Arabidopsis ABCB family and so had no apparent orthologs. However, AMN homologs were found in all dicotyledonous plants that possess the ability to either mycorrhize, nodulate, or both (Fig. 4). The restriction of AMNs to symbiotic lineages, and their highly symbiosis-associated expression, suggests that these genes fulfill a symbiosis-related function, since nonsymbiotic species such as Arabidopsis, which cannot nodulate or interact with arbuscular mycorrhizal fungi, would be expected to have lost symbiosis-related genes (Griesmann et al. 2018). This agrees with previous studies in which all three AMNs were identified as being part of a short list of genes conserved for arbuscular mycorrhizal symbiosis, using a comparative phylogenomics approach (Bravo et al. 2016; Delaux et al. 2014). We searched for AMN homologs in 38 species, 24 of which can form either AM or $\mathrm{RN}$ symbiosis, two of which can form ecto-mycorrhizal symbiosis but have lost their ability to form endomycorrhizal symbiosis, and the remaining 12 of which cannot establish associations with either rhizobia or mycorrhizal fungi (Supplementary Table S3) (Lambers and Teste 2013). Using Fisher's exact test, we determined the likelihood that the AMNs are encoded only in genomes of AM and RN symbiosis-forming species. The calculated $P$ values for AMN1 $(P=0.003), A M N 2(P=1.5 \mathrm{e}-09), A M N 3(P=5.2 \mathrm{e}-08)$ indicated that these genes are present in species that retained their ability to form symbiotic associations. Interestingly, only AMN2 was found to be present in the legume Lupinus angustifolius, which can nodulate but not form mycorrhizal associations, suggesting a requirement for AMN2 in nodulation. Conversely, since
A
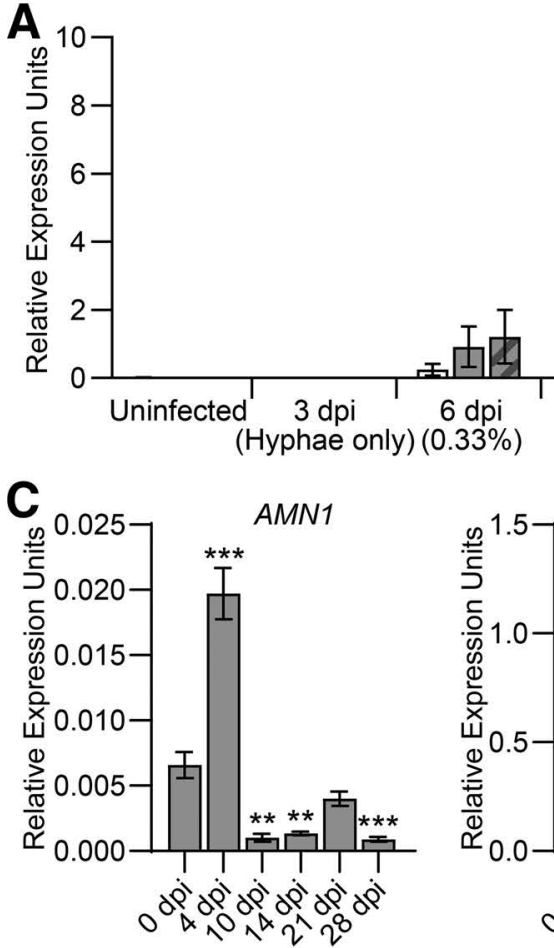
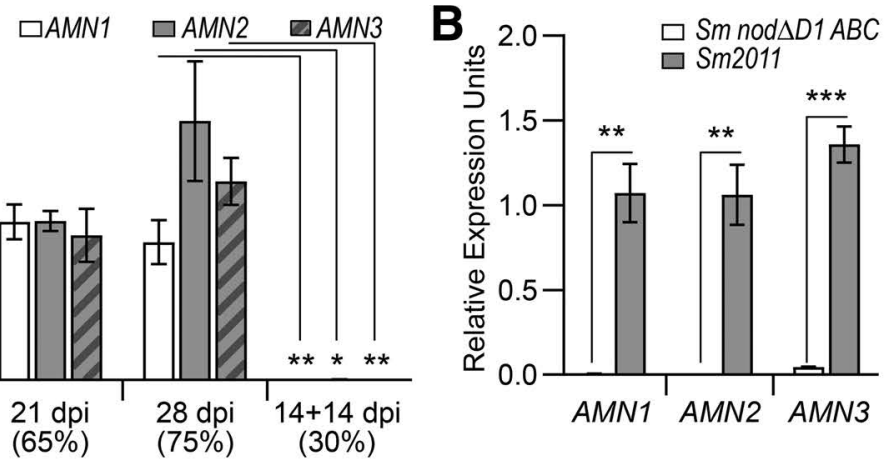

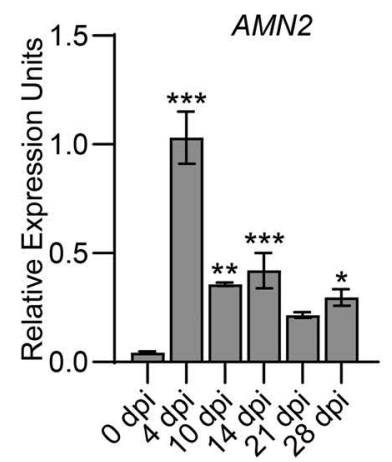

$9 \mathrm{dpi}$ $(20 \%)$

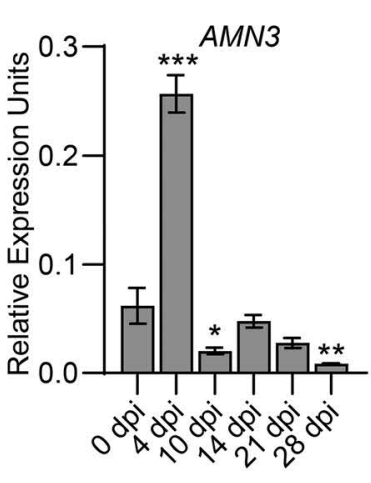

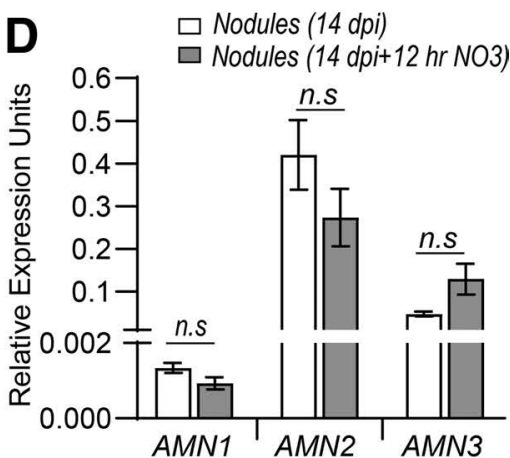

Fig. 2. Expression of three Medicago truncatula ABCB type transporters, $A M N 1, A M N 2$, and $A M N 3$, is induced upon infection by rhizobia and mycorrhizal fungi. A, Quantitative reverse transcription (RT)-PCR expression data showing expression of $A M N 1, A M N 2$, and $A M N 3$ increase over time in wild-type $M$. truncatula Jemalong A17 roots, inoculated with Rhizophagus irregularis. Approximate percentage of colonization in three representative samples is indicated within brackets next to the timepoint used for harvesting root tissue. For the $14+14$-dpi [days postinoculation] timepoint, colonization was allowed to proceed for 2 weeks, after which the plants were transferred to full nutrient-containing soil. B, Quantitative RT-PCR data showing induction of $A M N 1, A M N 2$, and $A M N 3$ in root hairs infected with Sinorhizobium meliloti and a control strain that is unable to produce nodulation factors. Values represent average of three biological replicates each. One asterisk $\left(^{*}\right)$ indicates $P<0.05$, two $\left(^{* *}\right) P<0.01$, and three $(* * *) P<0.001$, using the Student's $t$ test. Data were normalized using two housekeeping genes, $U B Q$ and Tip41. C, Quantitative RT-PCR data showing expression of the AMNs (ABCB for mycorrhization and nodulation genes) in nodules excised from Rm2011-inoculated $M$. truncatula roots at the timepoints indicated compared with root segments collected from the infection-susceptible zone of uninoculated roots $(0 \mathrm{dpi})$. One asterisk $\left({ }^{*}\right)$ denotes $P<0.05$, two (**) $P<0.01$, and three $(* * *) P<0.001$, using one-way analysis of variance and Dunnett's multiple comparisons test relative to uninoculated roots ( 0 dpi). D, Quantitative RT-PCR data showing induction of $A M N \mathrm{~s}$ in nodules harvested at $14 \mathrm{dpi}$ and compared with nodules harvested from comparable plants treated with $6 \mathrm{mM} \mathrm{KNO}_{3}$ for $12 \mathrm{~h}$. $\mathrm{N}_{\mathrm{s}} \mathrm{s}=$ not significant, using the Student's $t$ test. Bars depict standard error of the mean. Data were normalized using two housekeeping genes, $U B Q$ and $P T B$. 
the $L$. angustifolius (lupin) genome is considered to be relatively complete, having captured $>98 \%$ of the gene content, the absence of AMN1 and AMN3 suggests they are dispensable for nodulation but are required for interactions with AM fungi (Hane et al. 2017) (Fig. 4). The presence of AMN3 orthologs in the monocots Oryza sativa and Castanea mollissima, which form associations with ectomycorrhizal fungi, suggests a likely fundamental role for this transporter in both endo- and ectomycorrhizal symbiosis. Closest homologs from members of Brassicaceae (Arabidopsis thaliana) and Proteaceae (Nelumbo nucifera), which cannot establish either symbiosis, are included as outgroups in Figure 4.

\section{Isolation of amn mutants.}

Tnt1 insertion mutants were identified, and two alleles for each of three genes were obtained from the Noble Research

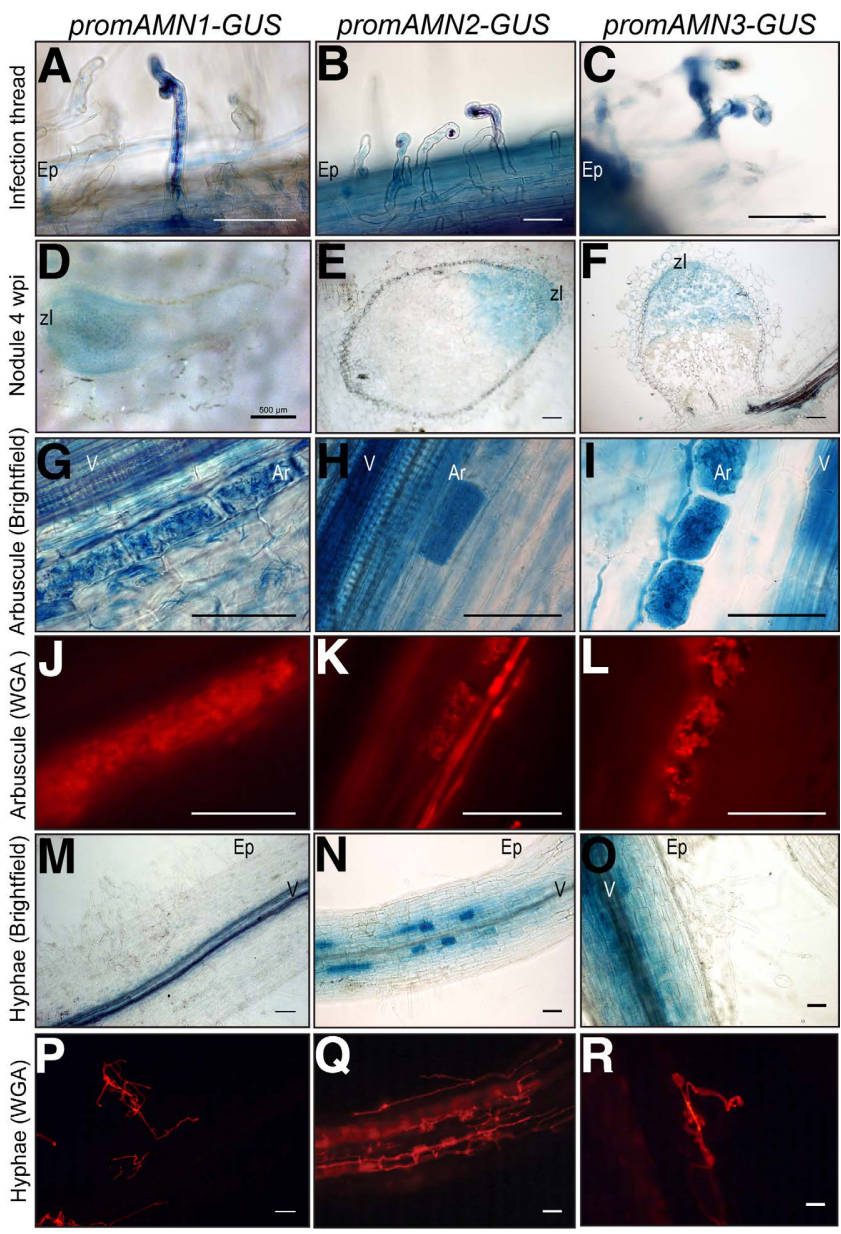

Fig. 3. Spatial expression patterns of $A M N 1, A M N 2$, and $A M N 3$ during symbiotic infection. A, B, and C, Medicago truncatula Jemalong A-17 wild-type hairy roots transformed with the Gateway destination vector pKGWFS7 containing the $A M N$ (ABCB for mycorrhization and nodulation gene) upstream promoter sequence fused to the reporter $\beta$-glucuronidase (GUS) and stained for GUS activity, using the chromogenic substrate X-GlcA (in blue). D, E, and $\mathbf{F}, A M N 1, A M N 2$, and $A M N 3$ are expressed in the cells containing infection threads and zone I and II of mature nodules at 4 weeks postinoculation (wpi) with Rm1021. Nodules were sectioned using a vibratome and sections are $50 \mu \mathrm{m}$ thick. Scale bar denotes $100 \mu \mathrm{m}$. G, H, and I, At 2 wpi with Rhizophagus irregularis, GUS activity is associated with cells hosting an arbuscule and $\mathbf{J}, \mathbf{K}$, and $\mathbf{L}$, the corresponding fluorescent images showing mycorrhizal fungi stained with wheat germ agglutinin (WGA). Individual arbuscule containing cells shown at $100 \times$ magnification. $\mathbf{M}, \mathbf{N}$, and $\mathbf{O}$, No GUS expression was detected upon initial contact with hyphae. $\mathbf{P}, \mathbf{Q}$, and $\mathbf{R}$, The corresponding fluorescent images showing mycorrhizal fungi stained with WGA. Roots from 12 to 15 transgenic plants were stained and their infection structures were analyzed. Scale bar denotes $50 \mu \mathrm{m}$. Ep = epidermis, $\mathrm{V}=$ vascular cylinder, $\mathrm{zI}=$ zone $\mathrm{I}$ (nodule meristem), Ar $=$ arbuscules.
Institute collection, amn1-1 (NF5606), amn1-2 (NF17134), amn2-1 (NF9733), amn3-1 (NF18154), and amn3-2 (NF8444), and the insertions were confirmed by sequencing to be at positions $+2291,+4616,+1548,+361$, and +408 , respectively (Fig. 5A; Supplementary Table S1). The inserted Tnt1 transposon sequences are all located within exons, which results in a series of missense mutations followed by a premature stop codon, and so are presumed null alleles. Heterozygous or homozygous plants were identified from these lines for each allele, were backcrossed to WT R108 to reduce the number of background mutations, and then, homozygous lines were identified from the backcrossed F2 population (Fig. 5B and C). No obvious developmental differences were seen in the mutants compared with WT (Fig. 5B). Reverse transcription-PCR was used to try and amplify the full-length messenger RNAs, using RNA samples from mycorrhized roots. UBIQUITIN was used as a positive control and it amplified from all samples. Full-length $A M N 1$, $A M N 2$, and $A M N 3$ transcripts were amplified from the WT samples but not from the mutants (Roy 2015). We then confirmed the presence of the Tnt1 transposon in the complementary DNA (cDNA), using a Tnt1-specific forward primer and gene-specific reverse primers, and the hybrid transcripts were sequenced to confirm the insertion positions. We also quantified partial transcript abundance of $A M N 1, A M N 2$, and $A M N 3$ in their respective mutant backgrounds (Supplementary Fig. S4B, C, and D). RNA was isolated from roots 4 weeks postinoculation (wpi) with $R$. irregularis. All three $A M N$ genes were expressed in inoculated WT roots. There was a $50 \%$ reduction in $A M N 2$ expression in infected roots of amn2-1 lines and a 60 to $65 \%$ decrease in $A M N 3$ transcript abundance in amn3-1 and amn3-2 plants, as compared with WT. In amn 1-1 and amn1-2 mutants, we detected an increase in AMN1 transcript abundance, likely due to the loss of negative feedback in the mutant.

\section{amn mutants can nodulate and form associations with mycorrhizal fungi.}

Symbiotic phenotypes of the $A M N$ mutants were tested upon infection with either rhizobia (Sinorhizobium meliloti Rm1021) or mycorrhizal fungi (Rhizophagus irregularis). No reproducible difference consistent across alleles was found for any mutant in the number of pink nodules or white nodules when compared with WT at 3 wpi (Fig. 5D). Nodules also showed no gross morphological differences. Similarly, none of the single mutants showed an arbuscular mycorrhizal colonization phenotype (Supplementary Fig. S4). Six double mutants were generated, amn1-1 amn2-1, amn1-2 amn2-1, amn1-1 amn3-1, amn1-2 amn3-2, amn2-1 amn3-1, and amn2-1 amn3-2. No growth defects or other nonsymbiotic phenotypes were seen in any of the mutant combinations. Moreover, these mutants developed a normal number of nodules (Fig. 5D).

We then tested AM colonization of the mutants 5 wpi with fresh $R$. irregularis chive-root inoculum. No differences in total colonization percentages consistent between alleles were observed for the single mutants or the double mutants (Fig. 5E; Supplementary Fig. S4). There were no obvious changes in arbuscule structures, which filled up the entire cell as in the WT (data not shown).

amn triple mutants exhibit an increase in nodule number.

To address the possibility of genetic redundancy, we crossed amn1-1 amn2-1 lines with amn2-1 amn3-2 lines. From the resulting F2 population, we isolated amn1-1 amn2-1 amn3-2 triple mutant lines homozygous for all three insertions. At 3 wpi with $\mathrm{Rm} 1021$ in soil, there was no change in nodule numbers compared with WT (Fig. 5D). At 1 wpi, there was a slight increase in the number of infection threads upon infection with Sm2011 LacZ (Fig. 5F) that was not statistically significant. However, 
the triple mutant showed a statistically significant increase in the number of nodules at 1 wpi (Fig. 5G). This phenotype was highly variable, seemed to be dependent on time of inoculation, and manifested at early timepoints or when nodule numbers were low (Supplementary Fig. S5). No changes in root architecture or nodule size were observed in the triple mutant compared with WT (Supplementary Fig. S6A, B, and C). We then tested mycorrhizal interactions and found no statistically significant changes in overall colonization percentage or arbuscule and vesicle formation in the triple mutant in two independent experiments (Fig. 5H).

\section{Symbiotic expression of $A M N 1, A M N 2$, and $A M N 3$ requires DMI3.}

As the $A M N$ genes are expressed during nodulation and mycorrhization, we hypothesized that these genes are controlled by the common symbiotic pathway. To test this hypothesis and to further place the $A M N$ genes relative to the common symbiosis signaling pathway, we tested their expression in ccamk, nfp, dmi3, $n s p 1, n s p 2, r a m 1$, and nin in the symbiotic context. Three-day-old seedlings were treated with $10 \mathrm{nM}$ NFs for $24 \mathrm{~h}$ and $A M N$ transcript levels were assessed (Fig. 6). WT plants treated with NFs resulted in the induction of all three genes, by three-, eight-, and

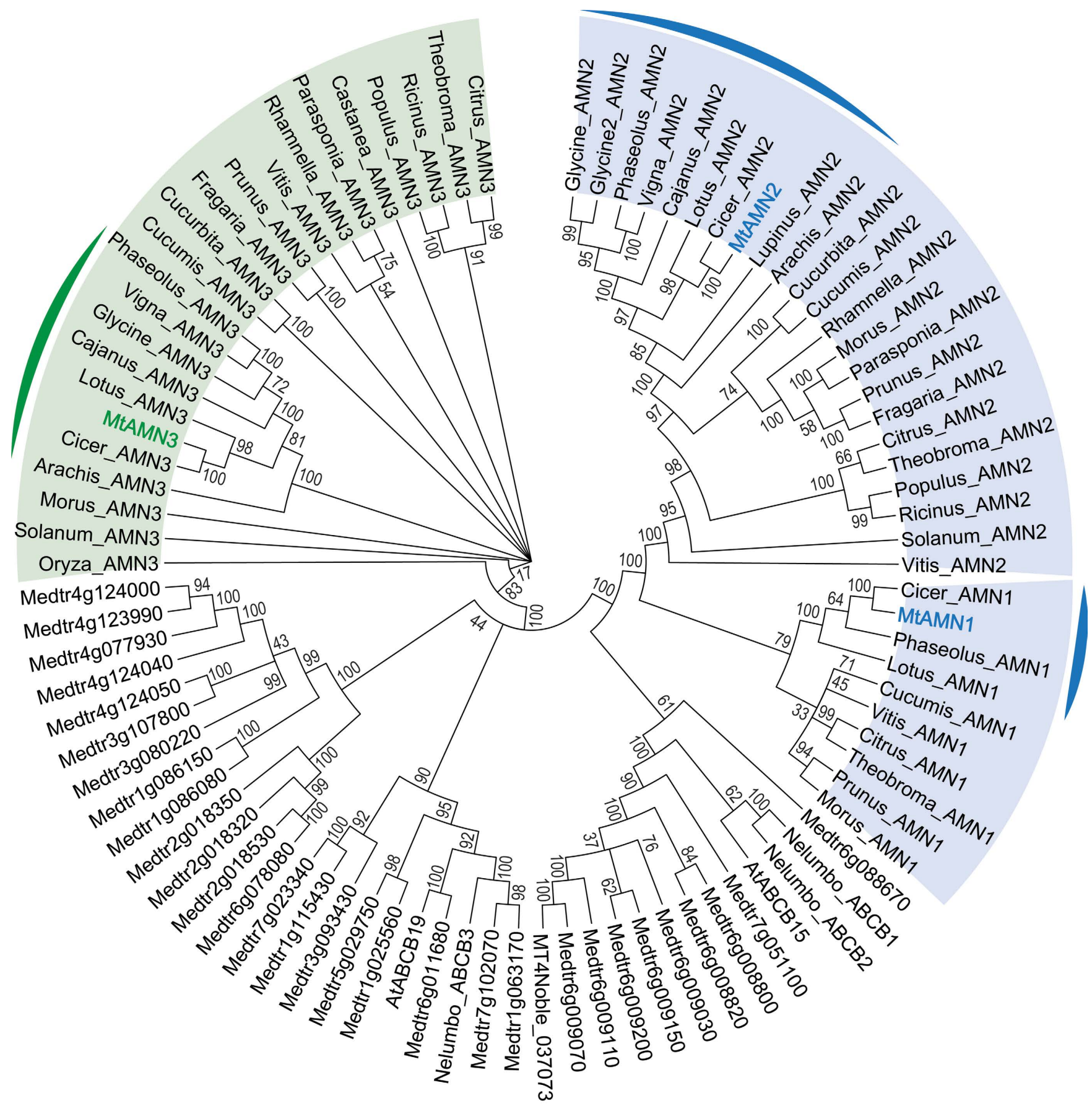

Fig. 4. Medicago truncatula $A M N 1, A M N 2$, and $A M N 3$ orthologs are retained in mycorrhizal fungi-interacting plant species. Phylogenetic tree showing ABC subfamily B members in M. truncatula and orthologous sequences for $A M N 1, A M N 2$, and $A M N 3$ from 26 plant species. AMN1, AMN2, and $A M N 3$ orthologs form distinct clusters comprised of plant species that can form associations with arbuscular mycorrhizal fungi. Members of the family Leguminosae, which can nodulate, form further subclusters, highlighted by colored brackets. AMN2 but not AMN1 or AMN3 was found in Lupinus angustifolius, which can nodulate but does not form mycorrhiza, while an ortholog in rice was only found for $A M N 3$ but not $A M N 1$ and $A M N 2$. A maximum likelihood tree was generated using amino acid sequences in Mega X and 1,000 bootstrap iterations. 
fourfold for $A M N 1, A M N 2$, and $A M N 3$, respectively (Fig. 6). The expression of $A M N 2$ and $A M N 3$ was also lower in $n f p$ and ccamk, while $A M N 1$ was similar to WT. Mutations in the two GRAS domain transcription factors NSP1 and NSP2 did not affect induction of the $A M N \mathrm{~N}$. On the other hand, loss of the transcription factor NIN caused a hyper induction of all three genes (Fig. 6A and B;
Supplementary Fig. S2D). These effects were mimicked in roots infected with $S$. meliloti at $7 \mathrm{dpi}$. All three AMNs were strongly upregulated relative to the water treated controls and their induction was dependent on DMI3 and was higher in nin (Fig. 6). In roots colonized by $R$. irregularis at $4 \mathrm{wpi}$, induction of all three $A M N s$ as well as that of the phosphate transporter MtPT4 was
A

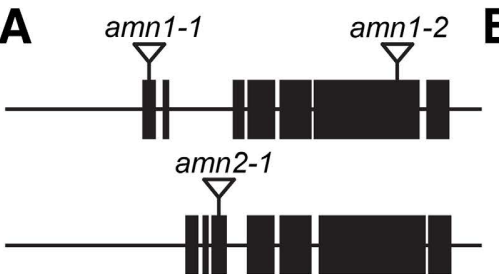

$\nabla$ amn3-2

Yamn3-1

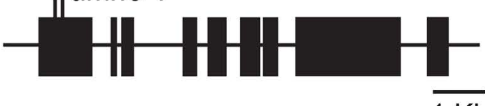

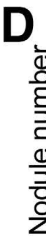

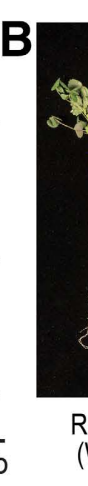

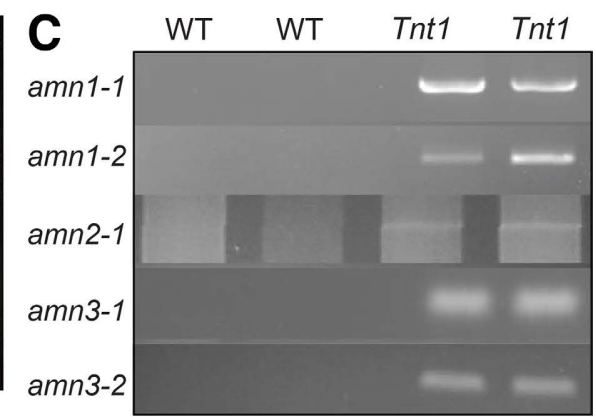

R-108 amn1-1 amn1-2 amn2-1 amn3-1 amn3-2
(WT)

amn3-2

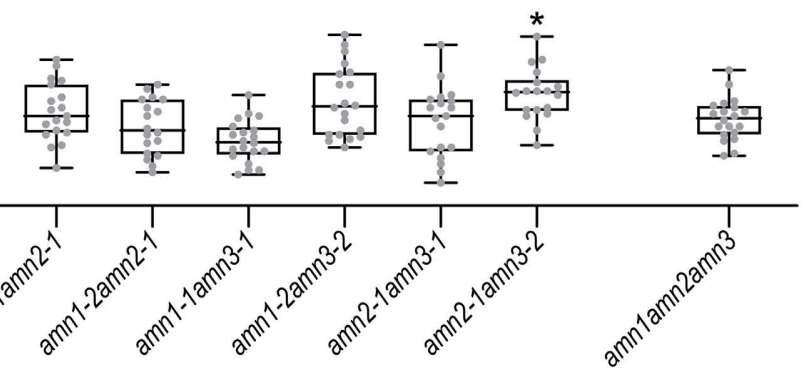

Vesicles

\section{E}

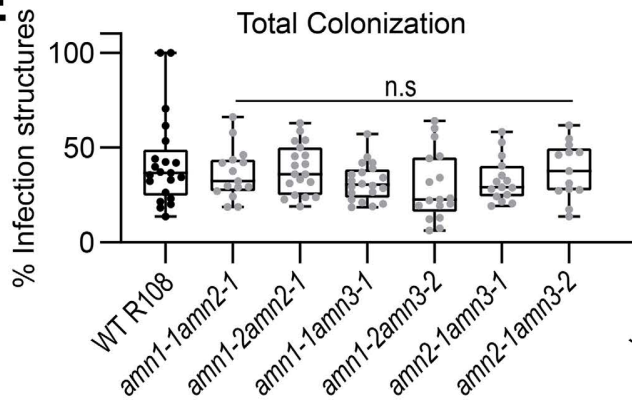

$\mathbf{F}$

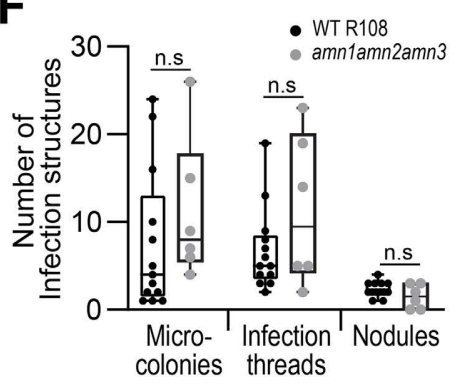

Arbuscules
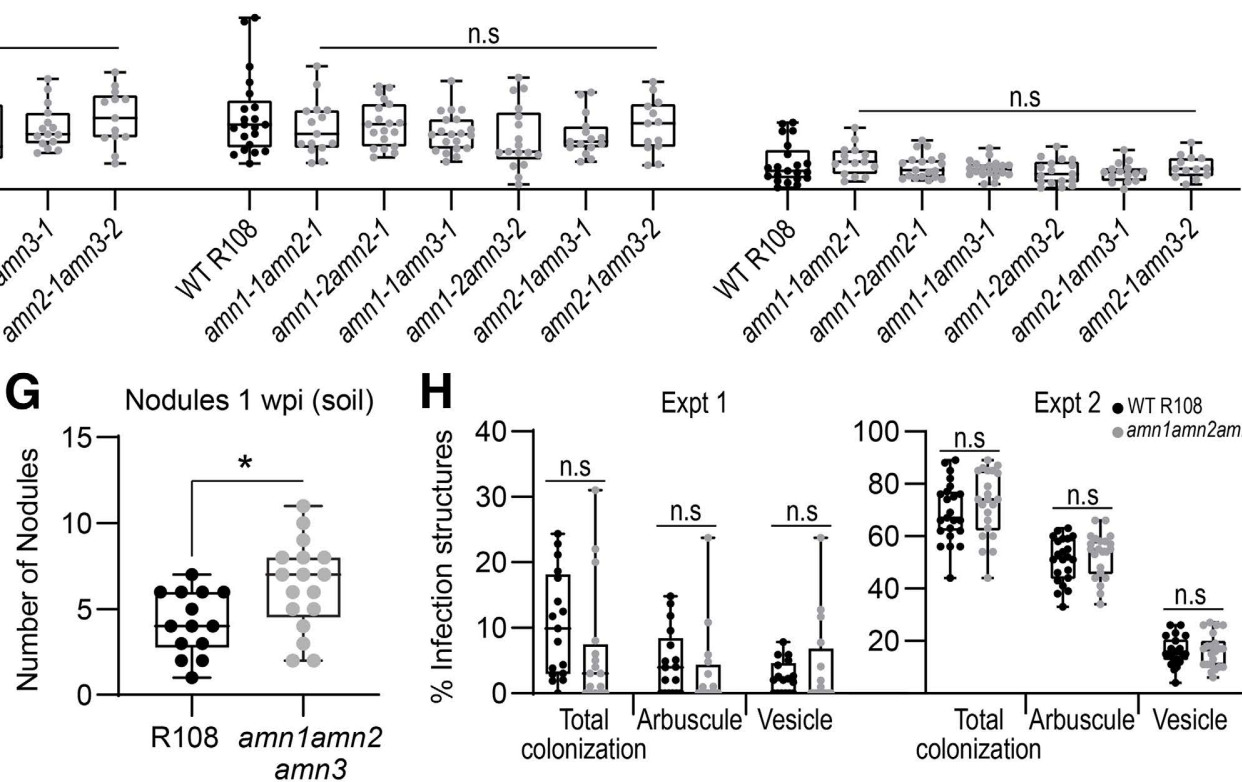

$\mathbf{H}$

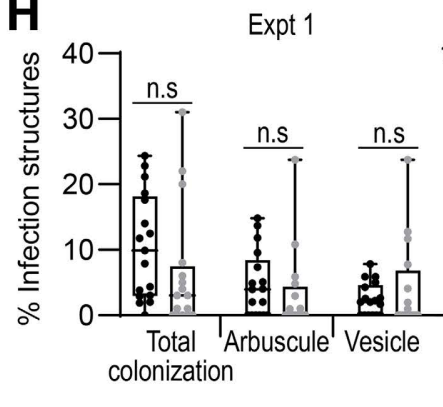

Expt 2 •WT R108 - amn1amn2amn3

Fig. 5. Symbiotic phenotypes of amn single, double, and triple mutant combinations. A, Gene structure diagram of $A M N 1$, $A M N 2$, and $A M N 3$ showing positions of the Tnt1 inserts in exon 1 (amn1-2) and exon 6 (amn1-2) of AMN1 and a single allele for AMN2 in exon 3 (amn2-1) and two alleles for AMN3, both in exon 1 (amn3-1, amn3-2). Note the similar exon and intron arrangement for AMN1 and AMN2, each with seven exons and six introns. B, Backcrossed Medicago truncatula R-108 mutant lines for amn1, amn2, and amn3 alleles show no obvious morphological and phenotypic abnormalities 3 weeks after infection with Sinorhizobium meliloti Rm1021, when compared with the wild type. C, Gel image confirming presence of Tnt1 insertions at predicted sites. Bands represent PCR-amplified products using complementary DNA generated from RNA extracted from mutant lines as the templates. A forward or reverse Tnt1 primer was combined with a gene-specific primer for the PCR reaction. D, Average nodule number 3 weeks postinoculation (wpi) with Rm1021. $n$ $=19,19,14,18,19,20,19,18,20,20,19,18$, and 20, respectively. E, Average mycorrhizal percentage colonization in single or double mutants. A one-way analysis of variance using Dunnett's multiple test compared with wild-type (WT) R108 was used to test statistical significance. n.s $=$ no statistical significance. Bars denote standard error of mean. $n=21,15,19,20,17,15$, and 13, respectively. F, Number of infection events in the amn1 amn 2 amn 3 triple mutant compared with WT R108 7 days postinoculation (dpi) with Rm1021 hemA:LacZ in a sand and TerraGreen mix. $n=13$ and 6, respectively. G, Number of nodules in the amn1 amn2 amn3 triple mutant compared with WT R108 7 dpi with Rm1021. $n=14$ to17; one asterisk $\left({ }^{*}\right)$ indicates $P<0.05$, two $(* *) P<$ 0.01 , and three (***) $P<0.001$, using the Student's $t$ test. H, Percent colonization of M. truncatula roots 7 wpi with Rhizophagus irregularis in the triple amn1 amn 2 amn 3 mutant compared with WT R108 in two independent experiments. $n=17$ and 16 and $n=23$ and 22 . In F and H, n.s $=$ not significant, using the Student's $t$ test. 
much lower in the dmi3 mutants (Fig. 6C). Although the AMNs were still induced in the raml mutant, their expression was strongly reduced compared with WT (Fig. 6C; Supplementary Fig. S2E).

\section{DISCUSSION}

The beneficial symbioses of plants with arbuscular mycorrhizal fungi and rhizobia require the activities of many transporters, including a number of $\mathrm{ABC}$ transporters. The functions of these transporters are diverse, including modulation of hormone
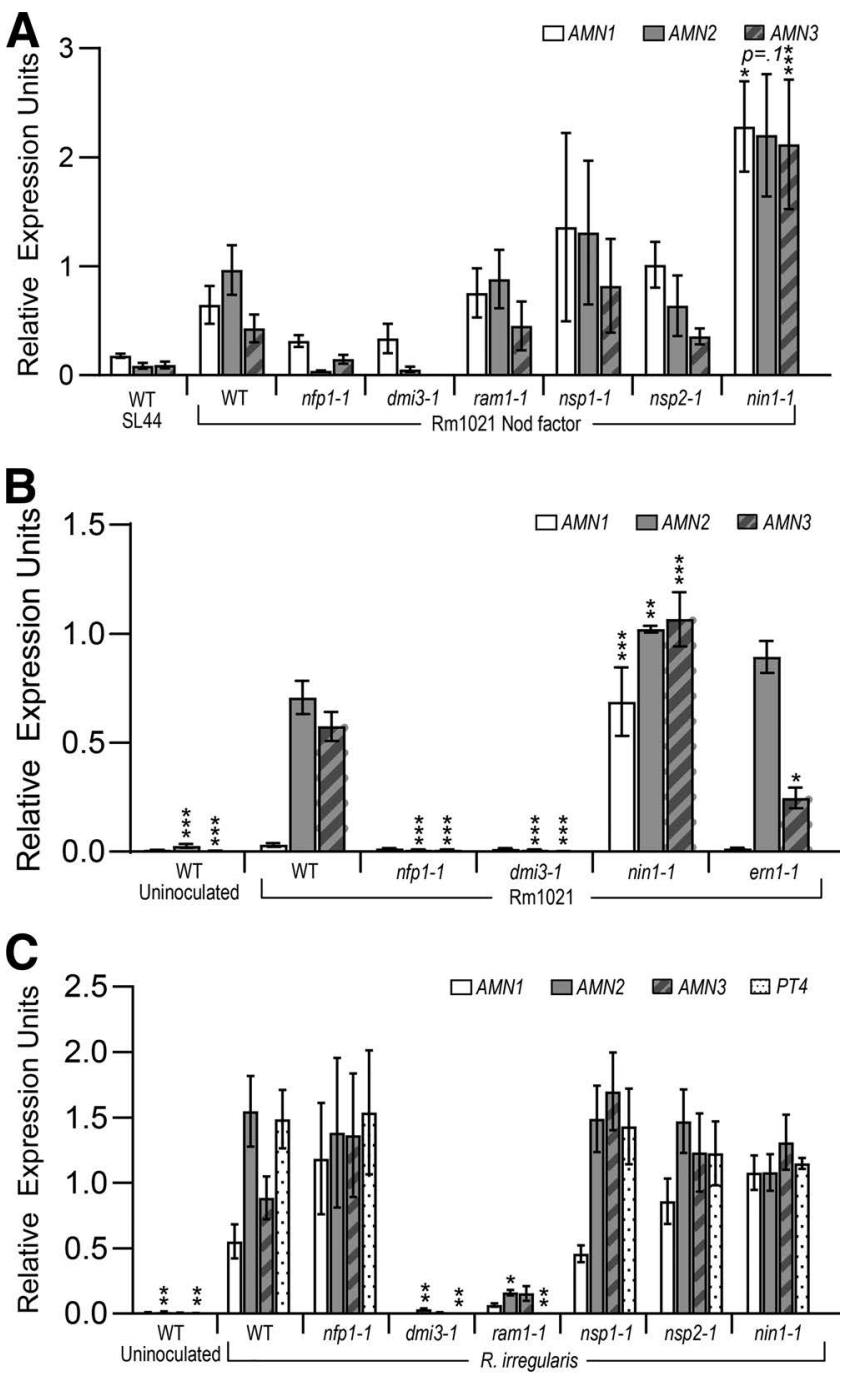

Fig. 6. Expression of $A M N 1, A M N 2$, and $A M N 3$ in different symbiotic pathway mutants. A, Relative expression of $A M N$ (ABCB for mycorrhization and nodulation) genes after treatment with $10 \mathrm{nM}$ nodulation factors (NFs) from Sinorhizobium meliloti Rm1021 or a matched extract from S. meliloti SL44, which is unable to produce NFs, in roots of wild-type (WT) Medicago truncatula (Jemalong A17) and six symbiotic pathway mutants. B, Relative expression of $A M N$ genes in roots of WT (Jemalong A17) and six symbiotic pathway mutants 7 days postinoculation with Rm1021 and uninoculated WT roots. C, Relative expression of $A M N$ genes and PT4 in WT (Jemalong A17) and mutant roots 4 weeks postinoculation with Rhizophagus irregularis and in uninoculated WT roots. Data are representative of three biological replicates, each comprised of three plants (mycorrhizal inoculation) or 10 seedlings (NF treatment and rhizobial inoculation). Bars depict standard error of mean. Data were normalized using two housekeeping genes, Tip41 and $U B Q$. Asterisks indicate a significant difference (one $\left[{ }^{*}\right] P<0.05$, two $\left[{ }^{* *}\right] P<0.01$, three $\left[{ }^{* * *}\right] P<$ 0.001 ) compared with the WT-inoculated samples, using one way analysis of variance followed by a Sidak's multiple comparison test for A, B and, C. distribution within the host tissues, cell-to-cell signaling within the plant, host-microbe signaling, nutrient provision to the symbiont, and metabolic activities associated with the uptake and distribution of acquired nutrients, e.g., ammonium and phosphate. We identified three ABC subfamily B transporters whose expression is primarily symbiotic, showing expression in infected tissues, in particular root hairs infected by rhizobia, and arbusculecontaining cells. Their expression in nodules appears confined to tissues forming infection threads, specifically root hairs, nodule primordia, and nodule zone II (infection thread zone). No expression of the $A M N$ genes was observed at the mycorrhizal fungi epidermal penetration sites, but it is still possible they are expressed transiently during penetration but not afterward. Given the asynchronous nature and relative scarcity of epidermal entry events by mycorrhiza, determining whether these genes are expressed during penetration may require a live-cell imaging approach. $A M N$ expression was also observed in noninfected cells, including the nodule meristem and the root vascular bundle and root tips, areas that are characterized by the expression of auxin markers. This is potentially interesting, since auxin is strongly associated with rhizobial infection. Studies using auxin markers suggest that an auxin maximum is formed in root hairs during rhizobial infection, and genetic and pharmacological evidence suggest that auxin biosynthesis and signaling are required for infection (Breakspear et al. 2014; Nadzieja et al. 2019). In addition, some links between auxin and the mycorrhizal symbiosis have been established (Etemadi et al. 2014).

Since multiple ABCBs in Arabidopsis can transport auxin and are auxin-inducible, we tested the expression of the AMNs to exogenous indole 3-acetic acid (IAA). None of the AMNs responded (Supplementary Fig. S3C), but the possibility that they may transport auxin bears further investigation. Other than auxin, the distribution of several other metabolites also matches that of the AMNs, including flavonoids and strigolactones. Several flavonoid biosynthetic genes have enhanced expression in root hairs of rhizobia-inoculated seedlings, including specific expression in cells containing infection threads and expression in the nodule zone containing infection threads (Breakspear et al. 2014; Chen et al. 2015; Roux et al. 2014). Similarly, genes for strigolactones and carotenoid biosynthesis, including CCD8 and D27, are increased in root hairs of rhizobia-inoculated seedlings and are expressed in the nodule zone containing infection threads (Breakspear et al. 2014; Roux et al. 2014). However, so far only ABCGs have been shown to have strigolactone transport activity (Banasiak et al. 2020; Kretzschmar et al. 2012). Similarly, an ABCG transporter was implicated in isoflavonoid release into the root exudate, suggesting involvement of a different ABC subfamily in transport of these compounds (Banasiak et al. 2013). It is tempting to speculate that some or all of the AMNs have lipid substrates, given that the $A M N$ genes are coexpressed with $M t A B C G 3$ in the arbuscule. Indeed, RAM1 was shown to regulate a transcriptional module that mediates lipid provision to arbuscular mycorrhizal fungi (Jiang et al. 2017; Luginbuehl et al. 2017). A suite of ABCG transporters with homology to Arabidopsis lipid transporters have been implicated in this process including $M t A B C G 3$, which is thought to be limited to mycorrhizal interactions.

Since $A M N 1, A M N 2$, and $A M N 3$ belong to the same ABC subfamily, are expressed during both endosymbioses, and show similar regulation by the common symbiotic pathway and by RAM1 in mycorrhizal roots, we hypothesize that the AMNs act redundantly (Fig. 7). This is supported by a small increase in nodule number in the triple mutant that is absent in the double and single mutants. This phenotype indicates a negative role of the transporter substrate during nodulation, for instance in secretion of toxic metabolites that might accumulate during the interaction or in the autoregulation of nodulation pathway. Further detailed analyses of additional triple mutant allelic lines at early nodulation or 
mycorrhization infection stages in the mutants, accompanied by metabolic profiling, might help reveal the role of the AMNs.

Our results indicate that the AMNs require the activation of CCaMK, which is thought to interpret the calcium oscillations that occur upon activation of the common symbiosis pathway (Charpentier 2018; Ehrhardt et al. 1996; Sieberer et al. 2012). We find that RAM1 is required for increased $A M N$ expression during mycorrhizal expression but not in response to NFs or rhizobia, providing a clear example of differential signaling downstream of CCaMK in the two symbioses. The raml mutant fails to develop arbuscules, so the requirement for RAM1 for $A M N$ expression may be indirect. In the context of nodulation, we found that induction of the $A M N$ genes is independent from NSP1, NSP2, and NIN. This is consistent with our previous root-hair transcriptomic studies of $\operatorname{nin}$ (Liu et al. 2019a). This earlier work also shows that expression of $A M N 1$ and $A M N 2$ in rhizobia-inoculated root hairs is also independent of ERN1. This is consistent with a common symbiotic role for these transporters, since ERN1 and NIN have roles that are restricted to nodulation (Guillotin et al. 2016; Kumar et al. 2020). Therefore, another common symbiotic transcription factor,
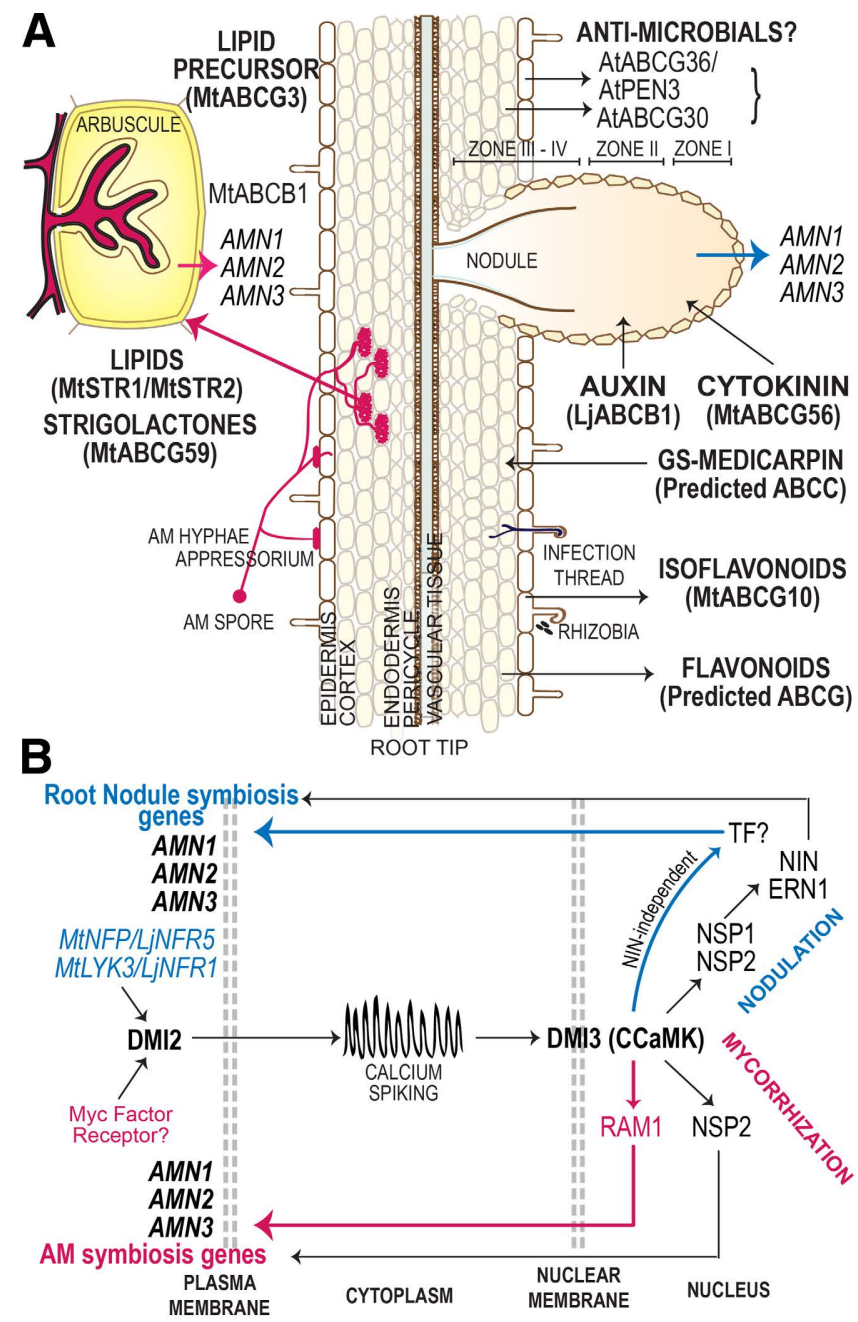

Fig. 7. A model for $A B C$ transporter involvement in arbuscular mycorrhization and the root nodule symbiosis. A, Illustration showing ABC transporters with roles in either nodulation or the arbuscular mycorrhizal symbiosis. Labels in bold denote predicted or identified substrates including lipids, strigolactones, isoflavonoids, and flavonoids, glutathione-conjugated (GS) medicarpin, putative antimicrobials, and cytokinin. Protein names are provided below the substrate. B, A schematic representation of the common symbiosis signaling pathways showing the positions of $A M N 1, A M N 2$, $A M N 3$ are predicted plasma-membrane $\mathrm{ABC}$ transporters that are dependent on components of this pathway. $\mathrm{TF}=$ transcription factor. such as IPD3 and IPD3L, must be involved in the regulation of these genes.

Our study has highlighted an interesting cohort of common symbiotic transporters, previously thought to be mycorrhizalspecific (Bravo et al. 2016), that are expressed in infected tissues during both root nodule and arbuscular mycorrhizal symbioses. Further phenotypic and genetic (i.e., generation of additional triple-mutant alleles) is needed to reveal their roles. In particular, the future identification of their substrates, regulation, and subcellular localizations should give novel insights into their function.

\section{MATERIALS AND METHODS}

Identification of full ABC transporters in M. truncatula.

Amino acid sequences for the Arabidopsis full ABC transporter were retrieved from Verrier et al. 2008 and used to run a Basic Local Alignment Search Test (BLAST) against the M. truncatula annotated protein sequences of genomes V4.0_reanno and V5 (Pecrix et al. 2018; Verrier et al. 2008). All annotated protein sequences were then analyzed for the presence of $\mathrm{ABC}$ signature motifs, transmembrane domains (TMD), and nucleotide binding domains (NBD) using PFAM. Sequences with two NBDs and two TMDs were termed full transporters. while those with only one of each were termed as half transporters. Protein sequences with additional domains were not considered further for analyses and were filtered out. Additionally, potential homologs in the V5 genome annotation were identified by aligning the known $\mathrm{ABC}$ transporter protein sequences with the V5 protein set. Proteins were selected as potential homologs if the alignment covered at least $75 \%$ of both the query and hit sequences, and the hit sequence was 50 to $200 \%$ as long as the query sequence.

\section{Retrieving orthologs of candidate genes from different species.}

Individual AMN protein sequences were used for BLAST searches against available protein sequences in 23 plant species in the National Center for Biotechnology Information database, using smart BLAST. Additionally, for Lotus and Oryza species, Lotus BLAST and Ensembl Plants databases were searched. A reciprocal BLAST was used to validate all putative orthologs. The protein IDs and sequences are provided in Supplementary Table S3.

\section{Phylogenetic tree construction.}

Amino acid sequences as listed in Supplementary Tables S1 and S3 were used for generating the trees and were aligned using Clustal W. Subsequently maximum likelihood phylogenetic trees were created with Mega X, using the JTT method and 1,000 bootstraps. The trees were exported in the newick format and were recreated using Figtree and bootstrap values superimposed in Adobe Illustrator.

\section{Statistical analyses.}

All statistical analyses were conducted using Graphpad Prism V8.1.0 and appropriate tests selected therein. Central bars represent median values. Fischer's exact test for gene retention was calculated in R studio and the code is included in Supplementary Table S3.

\section{Tnt1 mutant isolation and lines used in this study.}

Seeds for the lines amn1-1 (NF5606), amn1-2 (NF17341), amn2-1 (NF9733), amn3-1 (NF18141) and amn3-2 (NF8444) were obtained post reverse screening from the Noble Research Institute. Lines homozygous for each exonic mutant allele were selected using Tntl-specific primers and primers specific to $A M N 1, A M N 2$, or $A M N 3$. Primers are listed in Supplementary Table S2. All five mutant lines were compared with WT R108. 
For quantitative PCR (qPCR) experiments with root hairs, excised nodules and mycorrhizal fungi-colonized roots, WT Jemalong A17 plants were used. Mutants dmi3-1 (Wais et al. 2000), nin-1 (Marsh et al. 2007), ern1-1, nspl-1 (Catoira et al. 2000), nsp2-1 (Oldroyd and Long 2003), raml-1 (Gobbato et al. 2012), all in the Jemalong A17 background, were used in this study and were compared with WT Jemalong A17.

\section{Root tissue collection and RNA isolation.}

A root-hair harvesting protocol was adapted from Ramos and Bisseling (2003). Root tips were first removed, and the roots were plunged into liquid nitrogen contained in a Tefloncoated loaf tin (Dunelm Mill). A Daler Rowney number 2 filbert paint brush (Dunelm Mill) was used to brush root hairs off from the frozen root surface and hairs were collected in a polytetrafluoroethylene-coated vessel before RNA extraction. Around 120 to 150 roots were used per RNA sample. For IAA-treated roots, three-day-old seedlings were used, with 10 plants per biological replicate, and were treated with $1 \mu \mathrm{M}$ IAA for $3 \mathrm{~h}$. Root tips were removed before RNA was extracted. For comparing expression of the AMNs across mutants, either seedling roots treated with NF or roots nodulated with Rm1021 at 3 wpi were used. NF at a concentration of $10 \mu \mathrm{M}$ of either NF from WT Rm 1021 or the NF-deficient mutant SL44 were used to treat three-day-old seedlings. After $3 \mathrm{~h}$, seedling roots were collected, with each biological replicate comprising 10 roots each. For all mycorrhizal assays, roots from at least three plants were used for each biological replicate. Roots were washed and approximately 1-inch sections were collected, which comprised about one third of the base of the root. RNA was isolated using RNeasy plant micro kit (Qiagen), according to the manufacturer protocols, and its quality was analyzed using a Bioanalyser 2100 (Agilent). Excision of nodule samples and RNA extraction was previously described by de Bang et al. (2017).

\section{Primer efficiency calculations and qPCR.}

To calculate the efficiency of the qPCR primers used in this study, serially diluted cDNA samples prepared with $1 \mu \mathrm{g}$ of total RNA per sample, oligo dT primers, and Superscript III were used. qPCR was carried out to compare the relative abundance of a transcript across different sample types and treatment conditions after the cDNA was diluted 20-fold in double distilled water. Forward and reverse primers up to a final concentration of $0.2 \mathrm{mM}$ in $5 \mu \mathrm{l}$; $5 \mu \mathrm{l}$ of the diluted cDNA and $10 \mu \mathrm{l}$ of SYBR Green Taq Ready Mix (Sigma) were added to a total reaction volume of $20 \mu \mathrm{l}$. A minimum of three technical replicates each were used for three biological replicates per experiment. The cycling parameters on a Biorad $96 \mathrm{CFX}$ real time cycler used were $96^{\circ} \mathrm{C}$ for $5 \mathrm{~min}$ and $96^{\circ} \mathrm{C}$ for $10 \mathrm{~s}, 60^{\circ} \mathrm{C}$ for $15 \mathrm{~s}, / 72^{\circ} \mathrm{C}$ for $20 \mathrm{~s} 41$ times and followed up by a melt curve analysis from $65^{\circ} \mathrm{C}$ to $95^{\circ} \mathrm{C}$. The resultant cycle threshold $(\mathrm{Ct})$ values were were analyzed using the $\Delta \Delta \mathrm{Ct}$ method.

\section{Generation of stably transformed hairy roots in M. truncatula.}

The entire meristematic root tip was excised from overnightgerminated seedlings and the wounded end of the seedling was dipped into an Agrobacterium rhizogenes culture harboring the required construct that had been cultured over $48 \mathrm{~h}$. Twelve seedlings, each, were placed on modified Fahreus medium agar plates and were kept upright in controlled environment chambers for 7 to 10 days. Untransformed roots were excised and discarded, while the remaining roots were placed onto selection medium containing $20 \mu \mathrm{g}$ of kanamycin per milliliter. The plants were grown on plates till transformed hairy roots developed and were then transferred to soil for nodulation or mycorrhization assays.

\section{Histochemical localization of GUS.}

To visualize spatial patterns of gene expression, X-GlcA staining of GUS activity was performed. A solution with $196 \mu$ of 250 $\mathrm{mg}$ of X-GlcA (Melford) per milliliter of dimethyl formamide (DMF) was added to $50 \mathrm{ml}$ of Z-buffer $(100 \mathrm{mM}$ sodium phosphate buffer with $100 \mathrm{mM} \mathrm{Na} 2 \mathrm{HPO}_{4}, 100 \mathrm{mM} \mathrm{NaH} \mathrm{PO}_{4}$, $10 \mathrm{mM} \mathrm{KCl}$, and $1 \mathrm{mM} \mathrm{MgCl} 2$, adjusted to $\mathrm{pH}$ 7.4). Tissue samples were transferred to small Petri dishes, were covered in the staining solution, and were kept at $28^{\circ} \mathrm{C}$ in the dark for varying time periods ( $p A M N 1$ construct $>16 \mathrm{~h}, p A M N 2$ and $p A M N 36$ to $8 \mathrm{~h}$ ). After the desired color intensity developed, the staining solution was removed and the samples were washed three times with fresh GUS buffer.

\section{Infection assay and $\beta$-galactosidase staining.}

Roots infected with rhizobia containing pXLGD4 (phemA: LacZ) plasmids could be stained with X-GAL, a chromogenic dye that acts as a substrate for the enzyme $\beta$-galactosidase, encoded by the bacterial gene lacZ. Gluteraldehyde (Sigma) diluted to $2.5 \%$ in Z-buffer was vacuum infiltrated for $10 \mathrm{~min}$ and tissue was kept in solution for $1 \mathrm{~h}$ in the dark at room temperature. Samples were washed a minimum of three times with $10 \mathrm{ml}$ or more of Z-buffer. A final concentration of $40 \mathrm{mg}$ of X-gal per milliliter, dissolved in DMF, was added to the Z-buffer with $1 \%$ Triton- $\mathrm{X}$ and $1 \mathrm{mM}$ EDTA, and samples were transferred to $28^{\circ} \mathrm{C}$ in the dark overnight $(16 \mathrm{~h})$. The reaction was stopped by removing the staining solution and washing the roots at least three times with Z-buffer. The roots were then analyzed under a Nikon Eclipse 800 20x compound microscope, and the number of infection threads was quantified or images were captured.

\section{Nodulation assay.}

To compare nodule number between different genotypes, seeds were sterilized, scarified, and stratified as described before (Roy et al. 2017). Overnight-germinated seedlings were transferred to sterile TerraGreen and sharp sand mixed to a 1:1 ratio and were covered by a transparent lid to maintain humidity. Specifically, P40 (2-inch diagonals) trays were used for all nodulation assays. After allowing 7 days of growth, plants were inoculated with $1 \mathrm{ml}$ of rhizobia at a final absorbance of 0.02 to 0.05 at an optical density at $600 \mathrm{~nm}$, diluted in water. The plants were allowed to grow for 3 weeks under long-day conditions and were watered regularly. To count the number of nodules, roots were gently washed in water to remove soil.

\section{Mycorrhizal fungi colonization assay.}

To compare differences in percentage of colonization of Medicago roots by the fungus Rhizophagus irregularis, seedlings were germinated as described above. The seedlings were allowed to grow on plates for 7 days on distilled water agarose medium (1\% agarose) and were gently removed from the plates with forceps without damaging the roots. They were then transferred to Terra Green sand low-nutrient growth medium mixed with 25 to $30 \%$ chive inoculum containing roots of chive plants infected with spores of the mycorrhizal fungus. Plants were covered with a lid to maintain humidity for 1 week and were allowed to grow for 4 to 5 weeks before harvesting the root tissue. The fungus was visualized using an ink-staining protocol (Zhang et al. 2010). Roots were placed in float racks containing 2-ml tubes with drainage holes. The rack was placed in boiling $10 \% \mathrm{wt} / \mathrm{vol}$ potassium hydroxide solution for 12 min to clear the roots and the excess solution was allowed to drain off. The rack was placed into the staining solution containing 5\% ink and $10 \%$ acetic acid at $96^{\circ} \mathrm{C}$ for 6 min. Finally, the samples were washed with distilled water to remove excess stain. Roots were scored using the visual gridline intersection (VGI) method (McGonigle et al. 1990). 


\section{Wheat germ agglutinin staining of fungus.}

Harvested roots were washed with water to remove soil and were transferred to $50 \%$ ethanol for $4 \mathrm{~h}$. The ethanol was removed and samples were transferred to a $20 \% \mathrm{wt} / \mathrm{vol} \mathrm{KOH}$ solution at $28^{\circ} \mathrm{C}$. After 2 days, the solution was removed and samples were washed thoroughly with distilled water. Then, $0.1 \mathrm{M} \mathrm{HCl}$ was added for 1 to $2 \mathrm{~h}$, followed by a rinse, first with distilled water, and then, with phosphate buffered saline (PBS) buffer. WGAAlexa Flour 568 was added to PBS buffer to a final concentration of $0.2 \mu \mathrm{g} / \mathrm{ml}$ and samples were immersed in this staining solution overnight at $28^{\circ} \mathrm{C}$ in the dark. The next day, samples were rinsed and were observed under the microscope.

\section{ACKNOWLEDGMENTS}

The authors gratefully acknowledge and thank all members of the Oldroyd lab, especially T. Lee, and the Downie lab at the John Innes Centre for lively discussions and invaluable advice and support.

\section{AUTHOR-RECOMMENDED INTERNET RESOURCES}

Ensembl Plants database: http://plants.ensembl.org/index.html Lotus BLAST tool: https://lotus.au.dk/blast

M. truncatula genome v4.0_reanno: http://bioinfo3.noble.org/doblast

M. truncatula genome V5:

https://medicago.toulouse.inra.fr/MtrunA17r5.0-ANR

PFAM: http://pfam.xfam.org

\section{LITERATURE CITED}

Akiyama, K., and Hayashi, H. 2006. Strigolactones: Chemical signals for fungal symbionts and parasitic weeds in plant roots. Ann. Bot. 97: 925-931.

Banasiak, J., Biala, W., Staszków, A., Swarcewicz, B., Kepczynska, E., Figlerowicz, M., and Jasinski, M. 2013. A Medicago truncatula ABC transporter belonging to subfamily $\mathrm{G}$ modulates the level of isoflavonoids. J. Exp. Bot. 64:1005-1015.

Banasiak, J., Borghi, L., Stec, N., Martinoia, E., and Jasiński, M. 2020. The full-Size ABCG transporter of Medicago truncatula is involved in strigolactone secretion, affecting arbuscular mycorrhiza. Front. Plant Sci. $11: 18$.

Bravo, A., York, T., Pumplin, N., Mueller, L. A., and Harrison, M. J. 2016. Genes conserved for arbuscular mycorrhizal symbiosis identified through phylogenomics. Nat. Plants 2:15208.

Breakspear, A., Liu, C., Roy, S., Stacey, N., Rogers, C., Trick, M., Morieri, G., Mysore, K. S., Wen, J., Oldroyd, G. E., Downie, J. A., and Murray, J. D. 2014. The root hair "infectome" of Medicago truncatula uncovers changes in cell cycle genes and reveals a requirement for Auxin signaling in rhizobial infection. Plant Cell 26:4680-4701.

Buhian, W. P., and Bensmihen, S. 2018. Mini-review: Nod factor regulation of phytohormone signaling and homeostasis during rhizobialegume symbiosis. Front. Plant Sci. 9:1247.

Catoira, R., Galera, C., de Billy, F., Penmetsa, R. V., Journet, E. P., Maillet, F., Rosenberg, C., Cook, D., Gough, C., and Dénarié, J. 2000. Four genes of Medicago truncatula controlling components of a nod factor transduction pathway. Plant Cell 12:1647-1665.

Charpentier, M. 2018. Calcium signals in the plant nucleus: Origin and function. J. Exp. Bot. 69: 4165-4173.

Charpentier, M., Bredemeier, R., Wanner, G., Takeda, N., Schleiff, E., and Parniske, M. 2008. Lotus japonicus CASTOR and POLLUX are ion channels essential for perinuclear calcium spiking in legume root endosymbiosis. Plant Cell 20:3467-3479.

Charpentier, M., Sun, J., Vaz Martins, T., Radhakrishnan, G. V., Findlay, K., Soumpourou, E., Thouin, J., Véry, A.-A., Sanders, D., Morris, R. J., and Oldroyd, G. E. D. 2016. Nuclear-localized cyclic nucleotidegated channels mediate symbiotic calcium oscillations. Science 352: 1102-1105.

Chen, C., Gao, M., Liu, J., and Zhu, H. 2007. Fungal symbiosis in rice requires an ortholog of a legume common symbiosis gene encoding a $\mathrm{Ca} 2+/$ calmodulin-dependent protein kinase. Plant Physiol. 145:16191628.

Chen, D. S., Liu, C. W., Roy, S., Cousins, D., Stacey, N., and Murray, J. D. 2015. Identification of a core set of rhizobial infection genes using data from single cell-types. Front. Plant Sci. 6:575.
Chou, K.-C., and Shen, H.-B. 2010. Plant-mPLoc: A top-down strategy to augment the power for predicting plant protein subcellular localization. PLoS One 5:e11335.

Combier, J. P., Frugier, F., de Billy, F., Boualem, A., El-Yahyaoui, F., Moreau, S., Vernié, T., Ott, T., Gamas, P., Crespi, M., and Niebel, A. 2006. MtHAP2-1 is a key transcriptional regulator of symbiotic nodule development regulated by microRNA169 in Medicago truncatula. Genes Dev. 20:3084-3088.

de Bang, T. C., Lundquist, P. K., Dai, X., Boschiero, C., Zhuang, Z., Pant, P., Torres-Jerez, I., Roy, S., Nogales, J., Veerappan, V., Dickstein, R., Udvardi, M. K., Zhao, P. X., and Scheible, W.-R. 2017. Genome-wide identification of Medicago peptides involved in macronutrient responses and nodulation. Plant Physiol. 175:1669-1689.

Delaux, P. M., Bécard, G., and Combier, J. P. 2013. NSP1 is a component of the Myc signaling pathway. New Phytol. 199:59-65.

Delaux, P. M., Varala, K., Edger, P. P., Coruzzi, G. M., Pires, J. C., and Ané, J. M. 2014. Comparative phylogenomics uncovers the impact of symbiotic associations on host genome evolution. PLoS Genet. 10: e 1004487.

Ehrhardt, D. W., Wais, R., and Long, S. R. 1996. Calcium spiking in plant root hairs responding to Rhizobium nodulation signals. Cell. 85 673-681.

Etemadi, M., Gutjahr, C., Couzigou, J. M., Zouine, M., Lauressergues, D., Timmers, A., Audran, C., Bouzayen, M., Bécard, G., and Combier, J. P. 2014. Auxin perception is required for arbuscule development in arbuscular mycorrhizal symbiosis. Plant Physiol. 166:281-292.

Feng, F., Sun, J., Radhakrishnan, G. V., Lee, T., Bozsóki, Z., Fort, S., Gavrin, A., Gysel, K., Thygesen, M. B., Andersen, K. R., Radutoiu, S., Stougaard, J., and Oldroyd, G. E. D. 2019. A combination of chitooligosaccharide and lipochitooligosaccharide recognition promotes arbuscular mycorrhizal associations in Medicago truncatula. Nat. Commun. 10:5047.

Fournier, J., Teillet, A., Chabaud, M., Ivanov, S., Genre, A., Limpens, E., de Carvalho-Niebel, F., and Barker, D. G. 2015. Remodeling of the infection chamber before infection thread formation reveals a two-step mechanism for rhizobial entry into the host legume root hair. Plant Physiol. 167:1233-1242.

Genre, A., Chabaud, M., Balzergue, C., Puech-Pagès, V., Novero, M., Rey, T., Fournier, J., Rochange, S., Bécard, G., Bonfante, P., and Barker, D. G. 2013. Short-chain chitin oligomers from arbuscular mycorrhizal fungi trigger nuclear $\mathrm{Ca}^{2+}$ spiking in Medicago truncatula roots and their production is enhanced by strigolactone. New Phytol. 198:190-202.

Gherbi, H., Markmann, K., Svistoonoff, S., Estevan, J., Autran, D., Giczey, G., Auguy, F., Péret, B., Laplaze, L., Franche, C., Parniske, M., and Bogusz, D. 2008. SymRK defines a common genetic basis for plant root endosymbioses with arbuscular mycorrhiza fungi, rhizobia, and Frankia bacteria. Proc. Natl. Acad. Sci. U.S.A. 105:4928-4932.

Gleason, C., Chaudhuri, S., Yang, T., Muñoz, A., Poovaiah, B. W., and Oldroyd, G. E. 2006. Nodulation independent of rhizobia induced by a calcium-activated kinase lacking autoinhibition. Nature 441:11491152

Gobbato, E., Marsh, J. F., Vernié, T., Wang, E., Maillet, F., Kim, J., Miller, J. B., Sun, J., Bano, S. A., Ratet, P., Mysore, K. S., Dénarié, J., Schultze M., and Oldroyd, G. E. 2012. A GRAS-type transcription factor with a specific function in mycorrhizal signaling. Curr. Biol. 22:2236-2241.

Griesmann, M., Chang, Y., Liu, X., Song, Y., Haberer, G., Crook, M. B., Billault-Penneteau, B., Lauressergues, D., Keller, J., Imanishi, L., Roswanjaya, Y. P., Kohlen, W., Pujic, P., Battenberg, K., Alloisio, N., Liang, Y., Hilhorst, H., Salgado, M. G., Hocher, V., Gherbi, H., Svistoonoff, S., Doyle, J. J., He, S., Xu, Y., Xu, S., Qu, J., Gao, Q. Fang, X., Fu, Y., Normand, P., Berry, A. M., Wall, L. G., Ané, J. M., Pawlowski, K., Xu, X., Yang, H., Spannagl, M., Mayer, K. F. X., Wong, G. K., Parniske, M., Delaux, P. M., and Cheng, S. 2018. Phylogenomics reveals multiple losses of nitrogen-fixing root nodule symbiosis. Science 361 :eaat 1743.

Guan, D., Stacey, N., Liu, C., Wen, J., Mysore, K. S., Torres-Jerez, I., Vernié, T., Tadege, M., Zhou, C., Wang, Z. Y., Udvardi, M. K., Oldroyd, G. E., and Murray, J. D. 2013. Rhizobial infection is associated with the development of peripheral vasculature in nodules of Medicago truncatula. Plant Physiol. 162:107-115.

Guillotin, B., Couzigou, J.-M., and Combier, J.-P. 2016. NIN is involved in the regulation of arbuscular mycorrhizal symbiosis. Front. Plant Sci. 7: 1704

Gutjahr, C., and Parniske, M. 2013. Cell and developmental biology of arbuscular mycorrhiza symbiosis. Annu. Rev. Cell Dev. Biol. 29: 593-617.

Gutjahr, C., Radovanovic, D., Geoffroy, J., Zhang, Q., Siegler, H., Chiapello, M., Casieri, L., An, K., An, G., Guiderdoni, E., Kumar, 
C. S., Sundaresan, V., Harrison, M. J., and Paszkowski, U. 2012. The half-size ABC transporters STR1 and STR2 are indispensable for mycorrhizal arbuscule formation in rice. Plant J. 69:906-920.

Hane, J. K., Ming, Y., Kamphuis, L. G., Nelson, M. N., Garg, G., Atkins, C. A., Bayer, P. E., Bravo, A., Bringans, S., Cannon, S., Edwards, D., Foley, R., Gao, L. L., Harrison, M. J., Huang, W., Hurgobin, B., Li, S., Liu, C. W., McGrath, A., Morahan, G., Murray, J., Weller, J., Jian, J., and Singh, K. B. 2017. A comprehensive draft genome sequence for lupin (Lupinus angustifolius), an emerging health food: Insights into plant-microbe interactions and legume evolution. Plant Biotechnol. J. 15:318-330.

Hartmann, R. M., Schaepe, S., Nübel, D., Petersen, A. C., Bertolini, M., Vasilev, J., Küster, H., and Hohnjec, N. 2019. Insights into the complex role of GRAS transcription factors in the arbuscular mycorrhiza symbiosis. Sci. Rep. 9:3360.

Held, M., Hou, H., Miri, M., Huynh, C., Ross, L., Hossain, M. S., Sato, S., Tabata, S., Perry, J., Wang, T. L., and Szczyglowski, K. 2014. Lotus japonicus cytokinin receptors work partially redundantly to mediate nodule formation. Plant Cell 26:678-694.

Hirsch, S., Kim, J., Muñoz, A., Heckmann, A. B., Downie, J. A., and Oldroyd, G. E. 2009. GRAS proteins form a DNA binding complex to induce gene expression during nodulation signaling in Medicago truncatula. Plant Cell 21:545-557.

Hirsch, S., and Oldroyd, G. E. 2009. GRAS-domain transcription factors that regulate plant development. Plant Signal. Behav. 4:698-700.

Horváth, B., Yeun, L. H., Domonkos, A., Halász, G., Gobbato, E., Ayaydin, F., Miró, K., Hirsch, S., Sun, J., Tadege, M., Ratet, P., Mysore, K. S., Ané, J. M., Oldroyd, G. E., and Kaló, P. 2011. Medicago truncatula IPD3 is a member of the common symbiotic signaling pathway required for rhizobial and mycorrhizal symbioses. Mol. Plant-Microbe Interact 24:1345-1358.

Hürter, A. L., Fort, S., Cottaz, S., Hedrich, R., Geiger, D., and Roelfsema, M. R. G. 2018. Mycorrhizal lipochitinoligosaccharides (LCOs) depolarize root hairs of Medicago truncatula. PLoS One 13:e0198126.

Jardinaud, M.-F., Boivin, S., Rodde, N., Catrice, O., Kisiala, A., Lepage, A., Moreau, S., Roux, B., Cottret, L., Sallet, E., Brault, M., Emery, R. J., Gouzy, J., Frugier, F., and Gamas, P. 2016. A laser dissectionRNAseq analysis highlights the activation of cytokinin pathways by Nod factors in the Medicago truncatula root epidermis. Plant Physiol. 171:2256-2276.

Jarzyniak, K., Banasiak, J., Jamruszka, T., Pawela, A., Di Donato, M., Novák, O., Geisler, M., and Jasiński, M. 2021. Early stages of legume-rhizobia symbiosis are controlled by ABCG-mediated transport of active cytokinins. Nat. Plants 7:428-436.

Jiang, Y., Wang, W., Xie, Q., Liu, N., Liu, L., Wang, D., Zhang, X., Yang, C., Chen, X., Tang, D., and Wang, E. 2017. Plants transfer lipids to sustain colonization by mutualistic mycorrhizal and parasitic fungi. Science 356:1172-1175

Jin, Y., Chen, Z., Yang, J., Mysore, K. S., Wen, J., Huang, J., Yu, N., and Wang, E. 2018. IPD3 and IPD3L function redundantly in rhizobial and mycorrhizal symbioses. Front. Plant Sci. 9:267.

Käll, L., Krogh, A., and Sonnhammer, E. L. 2004. A combined transmembrane topology and signal peptide prediction method. J. Mol. Biol. 338: 1027-1036.

Kaló, P., Gleason, C., Edwards, A., Marsh, J., Mitra, R. M., Hirsch, S., Jakab, J., Sims, S., Long, S. R., Rogers, J., Kiss, G. B., Downie, J. A., and Oldroyd, G. E. D. 2005. Nodulation signaling in legumes requires NSP2, a member of the GRAS family of transcriptional regulators. Science 308:1786-1789.

Kretzschmar, T., Kohlen, W., Sasse, J., Borghi, L., Schlegel, M., Bachelier, J. B., Reinhardt, D., Bours, R., Bouwmeester, H. J., and Martinoia, E. 2012. A petunia ABC protein controls strigolactone-dependent symbiotic signalling and branching. Nature 483:341-344.

Kumar, A., Cousins, D. R., Liu, C.-W., Xu, P., and Murray, J. D. 2020. Nodule inception is not required for arbuscular mycorrhizal colonization of Medicago truncatula. Plants Basel 9:71.

Lambers, H., and Teste, F. P. 2013. Interactions between arbuscular mycorrhizal and non-mycorrhizal plants: Do non-mycorrhizal species at both extremes of nutrient availability play the same game? Plant Cell Environ. 36:1911-1915.

Liu, C. W., and Murray, J. D. 2016. The role of flavonoids in nodulation host-range specificity: An update. Plants Basel 5:33.

Liu, C. W., Breakspear, A., Guan, D., Cerri, M. R., Jackson, K., Jiang, S., Robson, F., Radhakrishnan, G. V., Roy, S., Bone, C., Stacey, N., Rogers, C., Trick, M., Niebel, A., Oldroyd, G. E. D., de Carvalho-Niebel, F., and Murray, J. D. 2019a. NIN acts as a network hub controlling a growth module required for rhizobial infection. Plant Physiol. 179: 1704-1722.
Liu, C. W., Breakspear, A., Roy, S., and Murray, J. D. 2015. Cytokinin responses counterpoint auxin signaling during rhizobial infection. Plant Signal. Behav. 10:e1019982.

Liu, C.-W., Breakspear, A., Stacey, N., Findlay, K., Nakashima, J., Ramakrishnan, K., Liu, M., Xie, F., Endre, G., de Carvalho-Niebel, F., Oldroyd, G. E. D., Udvardi, M. K., Fournier, J., and Murray, J. D. 2019b. A protein complex required for polar growth of rhizobial infection threads. Nat. Commun. 10:2848.

Liu, W., Kohlen, W., Lillo, A., Op den Camp, R., Ivanov, S., Hartog, M., Limpens, E., Jamil, M., Smaczniak, C., Kaufmann, K., Yang, W.-C., Hooiveld, G. J. E. J., Charnikhova, T., Bouwmeester, H. J., Bisseling, T., and Geurts, R. 2011. Strigolactone biosynthesis in Medicago truncatula and rice requires the symbiotic GRAS-type transcription factors NSP1 and NSP2. Plant Cell 23:3853-3865.

Luginbuehl, L. H., Menard, G. N., Kurup, S., Van Erp, H., Radhakrishnan, G. V., Breakspear, A., Oldroyd, G. E. D., and Eastmond, P. J. 2017. Fatty acids in arbuscular mycorrhizal fungi are synthesized by the host plant. Science 356:1175-1178

Luginbuehl, L. H., and Oldroyd, G. E. D. 2017. Understanding the arbuscule at the heart of endomycorrhizal symbioses in plants. Curr. Biol. 27:PR952-R963.

MacLean, A. M., Bravo, A., and Harrison, M. J. 2017. Plant signaling and metabolic pathways enabling arbuscular mycorrhizal symbiosis. Plant Cell 29:2319-2335.

Madsen, E. B., Madsen, L. H., Radutoiu, S., Olbryt, M., Rakwalska, M., Szczyglowski, K., Sato, S., Kaneko, T., Tabata, S., Sandal, N., and Stougaard, J. 2003. A receptor kinase gene of the LysM type is involved in legume perception of rhizobial signals. Nature 425:637-640.

Marsh, J. F., Rakocevic, A., Mitra, R. M., Brocard, L., Sun, J., Eschstruth, A., Long, S. R., Schultze, M., Ratet, P., and Oldroyd, G. E. 2007. Medicago truncatula NIN is essential for rhizobial-independent nodule organogenesis induced by autoactive calcium/calmodulin-dependent protein kinase. Plant Physiol. 144:324-335.

McGonigle, T. P., Miller, M H., Evans, D. G., Fairchild, G. L., and Swan, J. A. 1990. A new method which gives an objective measure of colonization of roots by vesicular-arbuscular mycorrhizal fungi. New Phytol. 115:495-501.

Müller, L. M., and Harrison, M. J. 2019. Phytohormones, miRNAs, and peptide signals integrate plant phosphorus status with arbuscular mycorrhizal symbiosis. Curr. Opin. Plant Biol. 50:132-139.

Murray, J. D., Karas, B. J., Sato, S., Tabata, S., Amyot, L., and Szczyglowski, K. 2007. A cytokinin perception mutant colonized by rhizobium in the absence of nodule organogenesis. Science 315:101-104.

Murray, J. D., Muni, R. R., Torres-Jerez, I., Tang, Y., Allen, S., Andriankaja, M., Li, G., Laxmi, A., Cheng, X., Wen, J., Vaughan, D., Schultze, M., Sun, J., Charpentier, M., Oldroyd, G., Tadege, M., Ratet, P., Mysore, K. S., Chen, R., and Udvardi, M. K. 2011. Vapyrin, a gene essential for intracellular progression of arbuscular mycorrhizal symbiosis, is also essential for infection by rhizobia in the nodule symbiosis of Medicago truncatula. Plant J. 65:244-252.

Nadzieja, M., Stougaard, J., and Reid, D. 2019. A toolkit for high resolution imaging of cell division and phytohormone signaling in legume roots and root nodules. Front. Plant Sci. 10:1000.

Ng, J. L. P., Hassan, S., Truong, T. T., Hocart, C. H., Laffont, C., Frugier, F., and Mathesius, U. 2015. Flavonoids and auxin transport inhibitors rescue symbiotic nodulation in the Medicago truncatula cytokinin perception mutant cre1. Plant Cell 27:2210-2226.

Oldroyd, G. E. D., and Long, S. R. 2003. Identification and characterization of nodulation-signaling pathway 2, a gene of Medicago truncatula involved in Nod actor signaling. Plant Physiol. 131:1027-1032.

Parniske, M. 2008. Arbuscular mycorrhiza: The mother of plant root endosymbioses. Nat. Rev. Microbiol. 6:763-775.

Pecrix, Y., Staton, S. E., Sallet, E., Lelandais-Brière, C., Moreau, S., Carrère, S., Blein, T., Jardinaud, M. F., Latrasse, D., Zouine, M., Zahm, M., Kreplak, J., Mayjonade, B., Satgé, C., Perez, M., Cauet, S., Marande, W., Chantry-Darmon, C., Lopez-Roques, C., Bouchez, O., Bérard, A., Debellé, F., Muños, S., Bendahmane, A., Bergès, H., Niebel, A., Buitink, J., Frugier, F., Benhamed, M., Crespi, M., Gouzy, J., and Gamas, P. 2018. Whole-genome landscape of Medicago truncatula symbiotic genes. Nat. Plants 4:1017-1025.

Pumplin, N., and Harrison, M. J. 2009. Live-cell imaging reveals periarbuscular membrane domains and organelle location in Medicago truncatula roots during arbuscular mycorrhizal symbiosis. Plant Physiol. 151:809-819.

Pumplin, N., Mondo, S. J., Topp, S., Starker, C. G., Gantt, J. S., and Harrison, M. J. 2010. Medicago truncatula Vapyrin is a novel protein required for arbuscular mycorrhizal symbiosis. Plant J. 61:482-494.

Pumplin, N., Zhang, X., Noar, R. D., and Harrison, M. J. 2012. Polar localization of a symbiosis-specific phosphate transporter is mediated by a 
transient reorientation of secretion. Proc. Natl. Acad. Sci. U.S.A. 109: E665-E672.

Radutoiu, S., Madsen, L. H., Madsen, E. B., Felle, H. H., Umehara, Y., Grønlund, M., Sato, S., Nakamura, Y., Tabata, S., Sandal, N., and Stougaard, J. 2003. Plant recognition of symbiotic bacteria requires two LysM receptor-like kinases. Nature 425:585-592.

Ramos, J., and Bisseling, T. 2003. A method for the isolation of root hairs from the model legume Medicago truncatula. J. Exp. Bot. 54: 2245-2250.

Riely, B. K., Lougnon, G., Ané, J. M., and Cook, D. R. 2007. The symbiotic ion channel homolog DMI1 is localized in the nuclear membrane of Medicago truncatula roots. Plant J. 49:208-216.

Roux, B., Rodde, N., Jardinaud, M. F., Timmers, T., Sauviac, L., Cottret, L., Carrère, S., Sallet, E., Courcelle, E., Moreau, S., Debellé, F., Capela, D., de Carvalho-Niebel, F., Gouzy, J., Bruand, C., and Gamas, P. 2014. An integrated analysis of plant and bacterial gene expression in symbiotic root nodules using laser-capture microdissection coupled to RNA sequencing. Plant J. 77:817-837.

Roy, S. 2015. Analysis of gene expression, regulation and function of three symbiotic ABC subfamily-B transporters in Medicago truncatula. Doctoral thesis. University of East Anglia, Norwich, U.K.

Roy, S., Liu, W., Nandety, R. S., Crook, A. Mysore, K. S., Pislariu, C. I., Frugoli, J., Dickstein, R., and Udvardi, M. K. 2020. Celebrating 20 years of genetic discoveries in legume nodulation and symbiotic nitrogen fixation. Plant Cell 32:15-41.

Roy, S., Robson, F., Lilley, J., Liu, C.-W., Cheng, X., Wen, J., Walker, S., Sun, J., Cousins, D., Bone, C., Bennett, M. J., Downie, J. A., Swarup, R., Oldroyd, G., and Murray, J. D. 2017. MtLAX2, a functional homologue of the Arabidopsis auxin influx transporter AUX1, is required for nodule organogenesis. Plant Physiol. 174:326-338.

Schauser, L., Roussis, A., Stiller, J., and Stougaard, J. 1999. A plant regulator controlling development of symbiotic root nodules. Nature 402: 191-195.

Schiessl, K., Lilley, J. L. S., Lee, T., Tamvakis, I., Kohlen, W., Bailey, P. C., Thomas, A., Luptak, J., Ramakrishnan, K., and Carpenter, M. D. 2019. NODULE INCEPTION recruits the lateral root developmental program for symbiotic nodule organogenesis in Medicago truncatula. Curr. Biol. 29:3657-3668.

Sieberer, B. J., Chabaud, M., Fournier, J., Timmers, A. C., and Barker, D. G. 2012. A switch in $\mathrm{Ca}^{2+}$ spiking signature is concomitant with endosymbiotic microbe entry into cortical root cells of Medicago truncatula. Plant J. 69:822-830.

Smit, P., Limpens, E., Geurts, R., Fedorova, E., Dolgikh, E., Gough, C., and Bisseling, T. 2007. Medicago LYK3, an entry receptor in rhizobial nodulation factor signaling. Plant Physiol. 145:183-191.
Smit, P., Raedts, J., Portyanko, V., Debellé, F., Gough, C., Bisseling, T., and Geurts, R. 2005. NSP1 of the GRAS protein family is essential for rhizobial Nod factor-induced transcription. Science 308: 1789-1791.

Suzaki, T., Yano, K., Ito, M., Umehara, Y., Suganuma, N., and Kawaguchi, M. 2012. Positive and negative regulation of cortical cell division during root nodule development in Lotus japonicus is accompanied by auxin response. Development 139:3997-4006.

Takanashi, K., Sugiyama, A., Sato, S., Tabata, S., and Yazaki, K. 2012. LjABCB1, an ATP-binding cassette protein specifically induced in uninfected cells of Lotus japonicus nodules. J. Plant Physiol. 169:322326.

Takeda, N., Maekawa, T., and Hayashi, M. 2012. Nuclear-localized and deregulated calcium- and calmodulin-dependent protein kinase activates rhizobial and mycorrhizal responses in Lotus japonicus. Plant Cell 24: 810-822.

Tirichine, L., Sandal, N., Madsen, L. H., Radutoiu, S., Albrektsen, A. S., Sato, S., Asamizu, E., Tabata, S., and Stougaard, J. 2007. A gain-offunction mutation in a cytokinin receptor triggers spontaneous root nodule organogenesis. Science 315:104-107.

van der Heijden, M. G., Martin, F. M., Selosse, M. A., and Sanders, I. R. 2015. Mycorrhizal ecology and evolution: The past, the present, and the future. New Phytol. 205:1406-1423.

Verrier, P. J., Bird, D., Burla, B., Dassa, E., Forestier, C., Geisler, M., Klein, M., Kolukisaoglu, U., Lee, Y., Martinoia, E., Murphy, A., Rea, P. A., Samuels, L., Schulz, B., Spalding, E. J., Yazaki, K., and Theodoulou, F. L. 2008. Plant ABC proteins-A unified nomenclature and updated inventory. Trends Plant Sci. 13:151-159.

Wais, R. J., Galera, C., Oldroyd, G., Catoira, R., Penmetsa, R. V., Cook, D., Gough, C., Denarié, J., and Long, S. R. 2000. Genetic analysis of calcium spiking responses in nodulation mutants of Medicago truncatula. Proc. Natl. Acad. Sci. U.S.A. 97:13407-13412.

Wang, W., Shi, J., Xie, Q., Jiang, Y., Yu, N., and Wang, E. 2017. Nutrient exchange and regulation in arbuscular mycorrhizal symbiosis. Mol. Plant 10:1147-1158.

Yano, K., Yoshida, S., Müller, J., Singh, S., Banba, M., Vickers, K. Markmann, K., White, C., Schuller, B., Sato, S., Asamizu, E., Tabata, S., Murooka, Y., Perry, J., Wang, T. L., Kawaguchi, M., Imaizumi-Anraku, H., Hayashi, M., and Parniske, M. 2008. CYCLOPS, a mediator of symbiotic intracellular accommodation. Proc. Natl. Acad. Sci. U.S.A. 105: 20540-20545.

Zhang, Q., Blaylock, L. A., and Harrison, M. J. 2010. Two Medicago truncatula half-ABC transporters are essential for arbuscule development in arbuscular mycorrhizal symbiosis. Plant Cell 22: 1483-1497. 